\title{
BRAIN POTENTIALS REFLECT RESIDUAL FACE PROCESSING IN A CASE OF PROSOPAGNOSIA
}

\author{
M. A. Bobes \\ Cuban Center for Neuroscience, Havana, Cuba \\ F. Lopera \\ University of Antioquia, Colombia
L. Díaz Comas, L. Galan, and F. Carbonell
Cuban Center for Neuroscience, Havana, Cuba \\ M. L. Bringas \\ International Neurological Rehabilitation Center, Havana, Cuba \\ M. Valdés-Sosa \\ Cuban Center for Neuroscience, Havana, Cuba
}

\begin{abstract}
Here, ERPs were employed to characterise the residual face processing of FE, a patient with extensive damage to the ventral temporal-occipital cortex and a dense prosopagnosia. A large N170 was present in $\mathrm{FE}$ and he performed well in tests of face structural processing. Covert recognition of the faces of personal acquaintances was demonstrated with P300 oddball experiments. The onset latency of the P300 effect was normal, indicating fast availability of covert memory. The scalp topography of this component in $\mathrm{FE}$ was different from that of the $\mathrm{P} 3 \mathrm{~b}$, presenting a centro-frontal maximum. $\mathrm{FE}$ also presented larger skin conductance responses to familiar than to unfamiliar faces. The amplitudes of both the single-trial P300s and the SCRs triggered by familiar faces were positively correlated with the degree of person-familiarity that $\mathrm{FE}$ had for the poser. He performed at chance when asked to select between the face of a familiar person and that of an unfamiliar person on the basis of explicit recognition, whereas he selected more the previously known face if the forced choice was based on trustworthiness or a vague sense of familiarity. The results suggest that in $\mathrm{FE}$, early face processing was relatively intact and covert recognition was fast. Neural structures involved in the processing of emotional or social cues possibly mediate the covert recognition present in FE.
\end{abstract}

\section{INTRODUCTION}

Prosopagnosia is a rare condition in which the identification of persons based on their faces is selectively impaired (Bodamer, 1947). Its existence suggests that face processing is segregated within the cerebral cortex. The study of this disorder has constrain cognitive models of face processing. However, the nature of the impairment can vary from one patient to another, indicating a

Correspondence should be addressed to Maria A. Bobes, Cuban Center for Neuroscience, CNIC, Ave 25 y 158, Cubanacan, Apartado 6880, La Habana, Cuba (Email: antonieta@cneuro.edu.cu).

This study was supported by the Cuban Center for Neuroscience, the University of Antioquia, and the León XIII Clinic (ISS of Colombia). Special thanks to patient FE and his wife AE for their participation. Sergio Della Sala, Ennio DeRenzi, Steve Hillyard, Shaun Vecera, Beatrice deGelder, Stefan Schweinberger, and one anonymous reviewer made helpful comments on previous versions of the manuscript. 
heterogeneous syndrome with distinct mental operations affected in different cases (e.g., De Renzi, Faglioni, Grossi, \& Nichelli, 1991). Furthermore, a striking finding (that must be handled by any theory) is that some patients with prosopagnosia can retain knowledge about faces that is used covertly, despite their severe inability to use it overtly (recently reviewed in Young \& Burton, 1999, and O'Reilly \& Farah, 1999). A better understanding of these two problems in prosopagnosia research-identifying impaired and preserved cognitive operations, and explaining covert knowledge - will help shape future modelling of face processing. Up to now, the two problems have been examined mainly with behavioural methods, although a handful of neuroimaging studies have been reported recently (e.g., Hadjikhani \& De Gelder, 2002; Marota, Genovese, \& Behrmann, 2001). In the present article we argue that the recording of event related potentials (ERPs), in combination with other methods, can contribute to the solution of these issues, and we describe pertinent data from a patient with prosopagnosia.

There are important disagreements on what is damaged, and on how to account for covert recognition in prosopagnosia (Köhler \& Moscovitch, 1997; O’Reilly \& Farah, 1999; Young \& Burton, 1999). Hypotheses on what is damaged in prosopagnosia are necessarily couched within the framework of models of normal face processing. One influential model was proposed by Bruce and Young (1986), in which a common stage of structural analysis (extracting an abstract, image invariant, representation of features and their configuration in familiar faces), is followed by at least three separate streams of processing. These streams enable either identity recognition for familiar faces, judgments on general characteristics of the face (such as age, sex, and race, also known as visual semantic codes), or recognition of emotional expressions, respectively. The first stream provides a connection from this initial structural stage and memories of specific faces (face recognition units or FRUs), whereas the latter two can process even unfamiliar faces.
According to this model (see Young, 1992) prosopagnosia could in principle arise from impairments either at the structural stage (affecting processing of both familiar and unfamiliar faces) or in the connection from the FRU and subsequent stages, in which case processing of unfamiliar faces would be relatively unaffected. These two types of impairment correspond roughly to the ideas of "apperceptive" and "associative" prosopagnosia (De Renzi et al., 1991). Burton, Young, Bruce, Johnston, and Ellis (1991) developed a neural network model based on the Bruce and Young (1986) scheme, in which each known face is stored in a FRU, which is linked to a person identity node (PIN), activation of which elicits familiarity. Similarly, there are name recognition units (NRUs) connected independently to the PINs. The PINs gives access to information stored about each person in a semantic information unit (SIU). The deficit in prosopagnosia could be simulated as a partial disconnection between FRU and PIN, which would produce a weakened sense of familiarity for faces that should be recognised (Burton et al., 1991; see Young \& Burton, 1999, for a detailed revision).

In contrast, it has been argued that prosopagnosia always originates from damage to early perceptual processing (Farah, O'Reilly, \& Vecera, 1993), leading to deficits in the processing of both familiar and unfamiliar faces. This alternative hypothesis has also been simulated in a computational model (Farah et al., 1993; see also O'Reilly \& Farah, 1999) with face input units (initial visual representations), hidden units, name units, and semantic units. Prosopagnosia is simulated by damaging the visual input units. Therefore, in this model the locus of impaired face recognition is found in early face perception, which contrasts with the Burton et al. (1991) model, where this locus is placed after extracting a structural representation of the face. Both models explain impaired familiarity for faces, and therefore have been further compared by testing their power to explain covert recognition (see Young \& Burton, 1999; O'Reilly \& Farah, 1999 , for more details), which would arise from the residual activation available in the network. 
Covert recognition is a puzzling effect that has been demonstrated by several behavioural phenomena, such as preserved priming from familiar (but unrecognised) faces when reading out the corresponding names, and increased ease in learning face-name pairs, or in matching two faces, when the faces were familiar (Bruyer et al., 1983; De Haan, Young, \& Newcombe, 1987; Young, Hellawell, \& De Haan, 1988). Covert recognition effects have also been revealed by eye-movement scan paths (Rizzo, Hurtig, \& Damasio, 1987) and by skin conductance responses (SCR; Bauer, 1984; Tranel \& Damasio, 1985). However, covert recognition is not found in all cases of prosopagnosia, and not all forms of covert processing may be present in those cases where it is found (Bauer, 1984; Etcoff, Freeman, \& Cave, 1991; McNeil \& Warrington, 1991; Newcombe, Young, \& De Haan, 1989), which is consistent with the heterogeneous nature of the disorder.

The two theories mentioned above both assume that covert knowledge is a degraded version of overt knowledge (Köhler \& Moscovitch, 1997). Another possibility is that covert and overt recognition are mediated by different types of memory representations (De Haan, Bauer, \& Greve, 1992; Köhler \& Moscovitch, 1997; Tranel, Damasio, \& Damasio, 1995). For example, Bauer (1984) argued that a visuo-limbic route, which bypasses the ventral pathway where face recognition takes place, is responsible for the enhanced skin conductance found for familiar faces in prosopagnosia. In the same vein, but with a different neuroanatomy, is a proposal by Ledoux (1995) that links from less elaborated sensory representations than required by conscious recollection could be established to the amygdala, and from there to emotional output systems.

More recently, Breen, Caine, and Coltheart (2000) have modified the Bruce and Young (1986) model of face recognition, including an independent pathway from the face recognition unit to an affective system, which could contribute to covert processing. In this model, the operation of the parallel pathway and its connections with the amygdala can explain covert recognition in prosopagnosia, as well as abnormal emotional processing in Capgras' syndrome (see also Breen \& Coltheart, 2001; Ellis \& Lewis, 2001; Lewis \& Ellis, 2001).

As mentioned before, most work in this field has used behavioural measures, which ultimately represent the final output of processing and cannot directly index intermediate stages. This limitation is also true for physiological measures such as SCR that reflect the activity of autonomic effectors. In addition, neither behaviour nor the SCR (which is a relatively sluggish response) can be used to study the temporal course of covert processing. In contrast, ERPs can monitor online the activity of different brain systems during cognition, helping to identify the stages of processing that are impaired in patients with neuropsychological syndromes. Given the excellent temporal resolution of ERPs, these can help define the timing of residual processing as well (Deouell, Hämäläinen, \& Bentin, 2000). ERP components related to faces could therefore be used to assess residual processing in prosopagnosia.

Stimulation with faces produces a characteristic ERP component that has been dubbed N170 (Bentin, Allison, Puce, Perez, \& McCarthy, 1996), which could be useful for the characterisation of early face processing in prosopagnosia. On the other hand, some ERP components are modulated by access to previous knowledge and may serve as signs of covert recognition. These potentials are especially useful in determining the time course over which memory codes are available (PerezAbalo, Rodríguez, Bobes, Gutierrez, \& ValdésSosa, 1994). An interesting application of this concept, using the P300 component, has been previously reported (Renault, Signoret, Debruille, Breton, \& Bolgert, 1989). To illustrate why this is important, consider computational simulations in which prosopagnosia is caused by partial damage to early visual stages. This should lead to a slower build-up of activity in the units responsible for perception of familiarity, which is a testable prediction with ERPs. The ERP signatures of covert familiarity (if present) should have longer latencies than in controls. 
The present study used ERPs to explore the residual face processing capacities of the severely prosopagnosic patient FE (Lopera \& Ardila, 1992). High-density recordings and recently developed statistical methods were employed to obtain a more precise characterisation of the effects of prosopagnosia on the N170 and P300 ERP components. Additionally, in the present study covert recognition was examined in forced-choice behavioural tasks and with the SCR for purposes of comparison with the preceding literature. Covert matching of unfamiliar faces had been previously evinced in this patient using ERPs (Bobes, Lopera, García, Díaz-Comas, Galán, \& Valdés-Sosa, 2003), by means of an identity-matching task that employed sequentially presented unfamiliar faces.

\section{CLINICAL DESCRIPTION OF FE}

$\mathrm{FE}$ is a right-handed male, with a high school degree. He suffered a closed head trauma (without skull fractures) in 1983 that produced bilateral intracerebral haematomas, which were surgically drained, and a coma lasting 2 weeks. Upon recovering consciousness, he could not recognise his wife and children by their faces, although he could do so by their voices. Lopera and Ardila (1992) describe the first two neuropsychological evaluations, in which he was found to be severely prosopagnosic.

A third assessment was performed in 1998, the time of the first ERP study, when he was 69 years old (for details see Bobes et al., 2003). The neurological examination was normal. FE maintained a dense prosopagnosia, even though he could recognise persons by nonfacial cues. This was confirmed by recognition tests of family photographs (1/50), and of photographs of celebrities (0/8). Behavioural evidence of covert processing was not achieved in a cross-domain semantic task similar to that described by Young et al. (1988, Experiment 1).

FE structural face processing was explored in 2002, using an adaptation of the test battery for face processing (CTBFP) described by Bruyer and Schweich (1991), including tests for the exploration of: (1) facial decision (faces vs. nonfaces);
(2) matching of facial features; (3) matching of faces; (4) age judgments; and (5) expression analysis (see Bobes et al., 2003). Performance of FE for all tasks was well above random level, achieving similar values to those of the normal control group, with indicates that structural processing is conserved in this patient.

\section{ANATOMICAL LOCALISATION OF THE LESIONS IN FE}

The extent of the brain lesions in $\mathrm{FE}$ was identified by magnetic resonance imaging (MRI). A threedimensional high-resolution structural MRI scan was performed on a 1.5 Tesla Siemens MAGNETOM SYMPHONY system (T1weighted FLASH sequence, TR/TE = 22/10, flip angle $30^{\circ}$, matrix size $256 \times 256$, FOV $256 \times 256$ ) yielding 176 sagital slices each with thickness of $1.0 \mathrm{~mm}$ and with in-plane resolution of $1 \times 1 \mathrm{~mm}$. Three-dimensional rendering of the brain was carried out with MRIcro software (http://www. psychology.nottingham.ac.uk/staff/cr1/mricro. html). The MRI image was co-registered in Talairach stereotaxic space using the normalisation functions of SPM99 (http://www.fil.ion.bpmf.ac. $\mathrm{uk} / \mathrm{spm} / \mathrm{spm} 99 . \mathrm{html}$ ) to allow comparison with other patients and with functional imaging studies (Brett, Leff, Rorden, \& Ashburner, 2001; Rorden $\&$ Brett, 2000). The Talairach coordinates of the across subject mean coordinates of the most significant voxels of the fusiform face areas (FFAs), as described by Kanwisher, McDermott, and Chun (1997), were located on both hemispheres of the normalized image.

The MRI evinced extensive bilateral damage in ventral occipitotemporal areas that was more severe on the right side (Figure 1). The lesions affected most of the right fusiform gyrus, whereas in the left hemisphere the lesion concerned the anterior and middle part of the fusiform gyrus and extended to the lingual and inferior temporal gyri. In the right hemisphere, the centre of FFA was at the inner superior border of the lesion, while for the left hemisphere it was located at the center of the lesioned area. However, other structures related to 

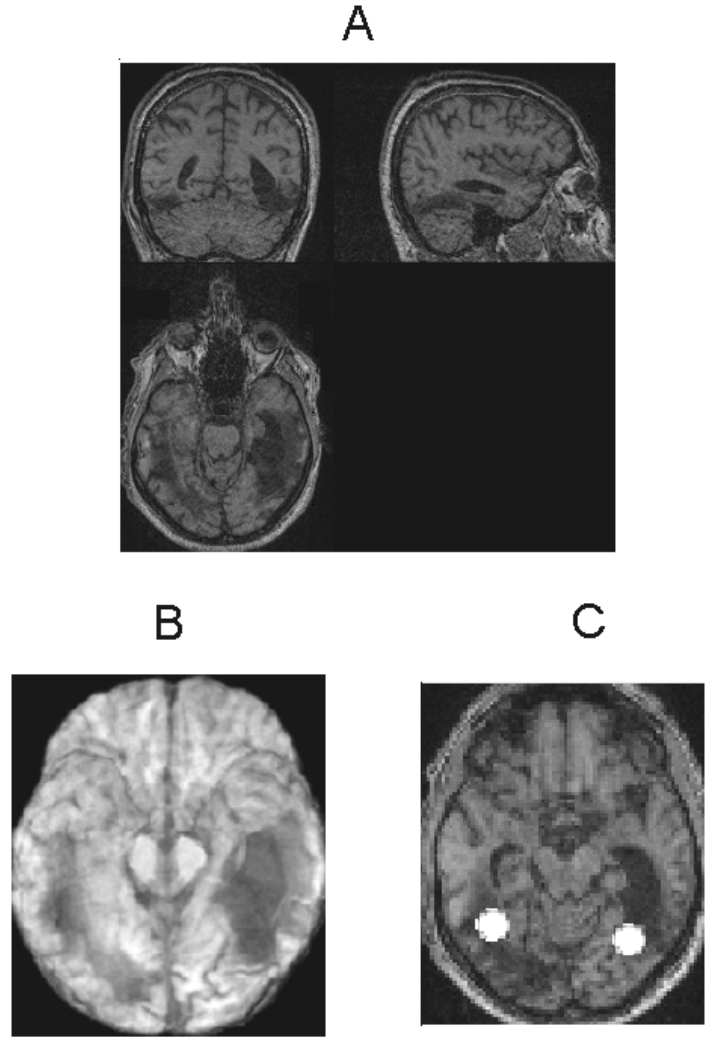

$z=-10$

Figure 1. MRI scans for FE. (A) T1 scan view projection. (B) Three-dimensional rendering of the ventral surface of the brain. (C) Transverse slice $(z=-10)$ of the normalised MRI image in which white circles indicate the Talairach coordinates of the across-subject mean coordinates of the most significant voxels of the fusiform face areas (FFAs), as described by Kanwisher, McDermott, and Chun (1997).

face processing, like the superior temporal sulcus, were intact for both hemispheres (see Figure 1).

\section{GENERAL METHODS FOR THE ERP EXPERIMENTS}

\section{Control participants}

A first group of five healthy adults, three males and two females, with ages ranging from 60 to 83 years $($ mean $=69)$ participated in the study as agematched controls. A second group of nine younger healthy adults (three males and six females), with ages ranging from 25 to 50 years, also participated in the study as naive controls. All the control participants had either high school or university degrees, all were right-handed (as ascertained by personal report), and all had normal or correctedto-normal vision. The controls participated as nonpaid volunteers.

\section{Face stimuli}

The stimuli consisted of digitised black-and-white photographs of faces, common objects, and houses, which were digitally processed to minimise differences in size, contrast, and overall luminance (see Bobes, Valdés-Sosa, \& Olivares, 1994). All of the face consisted of frontal views. Stimuli on the CRT subtended a vertical visual angle of 3.7 degrees and a horizontal visual angle of 2.5 degrees.

\section{ERP recording and analysis}

Subjects sat in front of a sVGA monitor (about $1 \mathrm{~m}$ from the observer) and were instructed to minimise body and eye movements during the experiments. Data acquisition was carried out either with 120 monopolar derivations, using electrodes mounted in an elastic cap homogeneously distributed over the scalp as well as two channels of EOG signals on a MEDICID-128 system (Neuronic, SA, Havana), or with $\mathrm{Ag}-\mathrm{AgCl}$ disk electrodes located at the locations of the $10 / 20$ international system on a MEDICID-III/E system. A notch filter with peak at $60 \mathrm{~Hz}$ was used and the signals were amplified by a factor of 10,000 and filtered between $0.5-$ $30 \mathrm{~Hz}$ ( $3 \mathrm{~dB}$ down). For the 120 channel recordings all electrodes were referred to linked earlobes and then re-reference to an average reference, and the inter-electrode impedance was always below 15 $\mathrm{kOhms}$. For the $10 / 20$ system, reference was located at the tip of the nose and the inter-electrode impedance was always below $10 \mathrm{kOhms.}$

The onset of the stimuli served to synchronise data collection. The EEG was digitally recorded at a sampling rate of $200 \mathrm{~Hz}$, with $800 \mathrm{~ms}$ epochs, and a $200 \mathrm{~ms}$ pre-stimulus baseline. Each EEG epoch was stored on magnetic disk, and was visually 
inspected offline. Those epochs with generalised artifacts or detectable eye-movement in the EOG were eliminated. In the 120 channels recording, electrodes with excessive noise were eliminated and substituted by an interpolation of the 11 closest neighbours. Averaged evoked responses were subjected to low-pass filtering under $5.5 \mathrm{~Hz}$. ERP amplitudes were corrected by subtracting the average pre-stimulus amplitude value.

\section{Statistical analysis}

Test of effects within individual cases used the single trials EEG epochs. Dependent sample, onesided, Student $t$ tests were used as the basic measure in a nonparametric permutation procedure (see Blair \& Karniski, 1993). This test is distribution free, it does not require assumptions about the underlying correlation structure, and it provides exact $p$-values for any number of subjects, time points, and recording sites, which allows for tests at multiple time points and electrodes while controlling for type I errors. This procedure enables the location and timing of the effects to be identified more precisely. Within-subject effects at the level of the control groups were tested with the same procedure just described, but applied to the average ERPs for the individuals.

To carry out the comparison between the patient and the group of controls we used an analysis of variance (ANOVA) with a between-subjects factor of group (patient vs. controls). We follow here the approach described in Mycroft, Mitchell, and Kay (2002), where only the variability from the control group is taken into account in the calculation of the error term. They propose a revised $F$ criterion to overcome the problems of differences in variability between patient and the control group. ${ }^{1}$
Scalp distributions of the ERP components were analysed by obtaining statistical parametric maps (SPM) from high-density electrode arrays in order to characterise the topography of the ERP components in greater detail. When testing for differences in scalp topography of a component between subjects and conditions, the amplitude values of the ERPs were normalised across electrodes by scaling with the vector norm as recommended by McCarthy and Wood (1985).

\section{EXPERIMENT 1: THE N170 IN FE}

The N170 was explored in FE with a paradigm used in previous studies (Bentin et al., 1996; Bentin \& Deouell, 2000; Eimer, 2000a; Rossion et al., 1999; Schweinberger, Pickering, Jentzsch, Burton, \& Kaufmann, 2002), in which the ERPs elicited by faces and objects were compared. In normal subjects the N170 at right temporal sites is larger for face than for object stimuli. In other words it is face-selective, a property that has served as a functional definition for the N170 in different situations. This component is not modulated by the familiarity of the face stimuli (Bentin \& Deouell, 2000; Eimer, 2000a; Rossion et al., 1999; Schweinberger et al., 2002), which is consistent with its relationship to early stages of face processing, prior to the activation of FRUs.

The N170 has been recorded in some cases of prosopagnosia, using the functional definition described above. In one case (patient PHD, reported by Eimer \& McCarthy, 1999), the N170 was substantially smaller than in controls. This case was very impaired in the Benton and Van Allen Facial recognition test (Benton \& Van Allen, 1968), and also presented difficulties in other

\footnotetext{
${ }^{1}$ These revised $F$-values were computed through Monte Carlo simulations (instead of using the tables in the article) and take into account the size of the control group $(N)$ and the ratio of variance $\left(\sigma^{2}\right)$ between the patient and controls. However, in our case we had to compute separate ANOVAs for different electrodes, the $\sigma^{2}$ of which is (in general) different, which implies a different $F$-value for each electrode. We chose the maximum of these $F$-values as a global decision threshold. The number of controls was $N=5$, the number of simulations was set to 30,000 , and $\sigma^{2}$ was estimated for each channel independently. For each of the 30,000 independent runs we computed the maximum of the $F$-values over the set of channels and calculated the $F$ value that partitions off the $5 \%$ rejection region. Thus, this value $F$ is the desired global decision threshold at the $5 \%$ significance level.
} 
visuo-perceptual tasks, which is congruent with damage to early stages of visual perception, and specifically to face structural processing. The N170 has been reported to be of normal amplitude in one case of developmental prosopagnosia (case YT), albeit lacking in face-specificity (Bentin, Deouell, \& Soroker, 1999). In another patient with acquired prosopagnosia (case XB), the N170 was unaffected (Rossion et al., 1999).

These divergent results underline the heterogeneous nature of prosopagnosia, and could be very informative if considered together with the details of the neuropsychological assessment of each case. $\mathrm{FE}$ presents an interesting contrast to PHD. The early face structural processing of $\mathrm{FE}$ is well conserved as ascertained by the CTBFP battery (see case description), whereas this type of processing seems to be severely affected in PHD. Given that $\mathrm{N} 170$ is attenuated in PHD, its conservation in FE would confirm the relationship of N170 to early face structural processing.

\section{Methods}

$\mathrm{FE}$ and five age-matched controls (described earlier) participated in this experiment. Three stimulus classes were used: unfamiliar faces, common objects, and houses. There were 20 different photographs of faces and 20 different photographs of objects, which were presented four times each, in addition to 15 different photographs of houses, which were presented only once each, for a total of 80 face, 80 object, and 15 house stimuli. Every stimulus was presented for $1000 \mathrm{~ms}$, following a pseudo random order. Subjects were instructed to report detection of the houses by pressing a key. The house stimuli were included as foils to control for attention and the corresponding ERPs are not considered further here. The subjects triggered the presentation of each stimulus by pressing a key. The 120 ERP channel montage was used (see earlier).

\section{Results and discussion}

Detection of the houses was highly accurate for both normal controls (ranging from 86.6 to $100 \%$ hit rates, mean $=95.98, S D=5.99)$, and for $\mathrm{FE}$ who only missed one house ( $93.3 \%$ hit rate). ERPs from posterior temporal electrodes sites obtained for faces and objects for the control group and $\mathrm{FE}$ are shown in Figure 2A. In the control group, the grand average waveform exhibited a prominent negativity around $190 \mathrm{~ms}$, which corresponds with the N170 component. The response was larger over the right hemisphere, and specifically over the posterior temporal electrodes. As shown in the figure, the amplitude of the N170 associated to faces was larger than the response to objects at T6 in the grand averaged waveform for the control group.

The effect of stimulus class was tested statistically by performing permutation analysis of the ERPs measures in the control group. The amplitude differences for the control group at T6 were significantly larger for faces than for objects $(p<$ $.05)$ between 185 and $205 \mathrm{~ms}$, which includes the N170 time region. A contrast of the difference in amplitude between the face and objects condition was carried out in each control subject based on the single trial EEG recordings (Table 1). This was done to assess the reliability of the N170 effect in individual subjects, so the results from $\mathrm{FE}$ could be better interpreted. The N170 amplitude was significantly larger for faces than for objects in all of the controls, indicating that it is a very reliable phenomenon. Figure 2B presents the histograms of ERP amplitudes for the face and object conditions in the control group.

In the recordings from patient $\mathrm{FE}$ a prominent negativity with a latency of $185 \mathrm{~ms}$ was found in the ERPs elicited by faces and objects (see Figure 2A).

Table 1. Results of statistical tests of the difference between N170 elicited by faces and by objects. Permutation $\mathrm{t}$ tests were carried out upon the single trials in each case at the T5, T6 derivations of the 10/20 system, and at PO3, PO4 of the 10/10 system

\begin{tabular}{lll}
\hline Case & \multicolumn{1}{c}{ Time region } & \multicolumn{1}{c}{ Electrodes } \\
\hline Control 1 & $185-210,255-270$ & T6, PO4 \\
Control 2 & $160-190$ & T6, PO4 \\
Control 3 & $145-180,235-280$ & T6 \\
Control 4 & $165-195,210-260$ & T6, PO3, PO4 \\
Control 5 & $285-295$ & T6 \\
Patient FE & $175-195$ & T5, PO3 \\
\hline
\end{tabular}


Control group

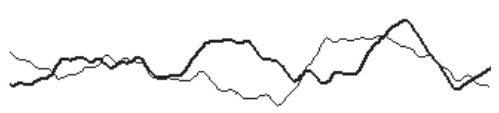

A

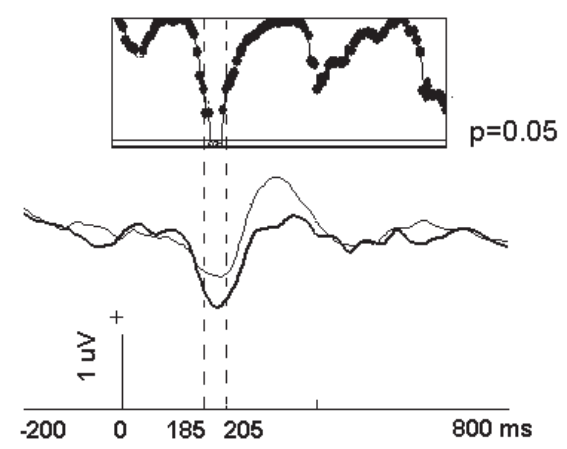

FE

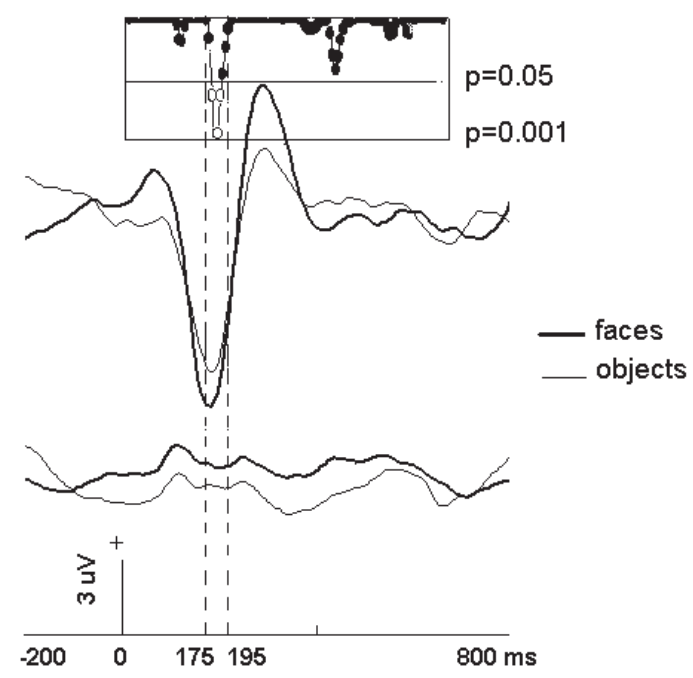

B
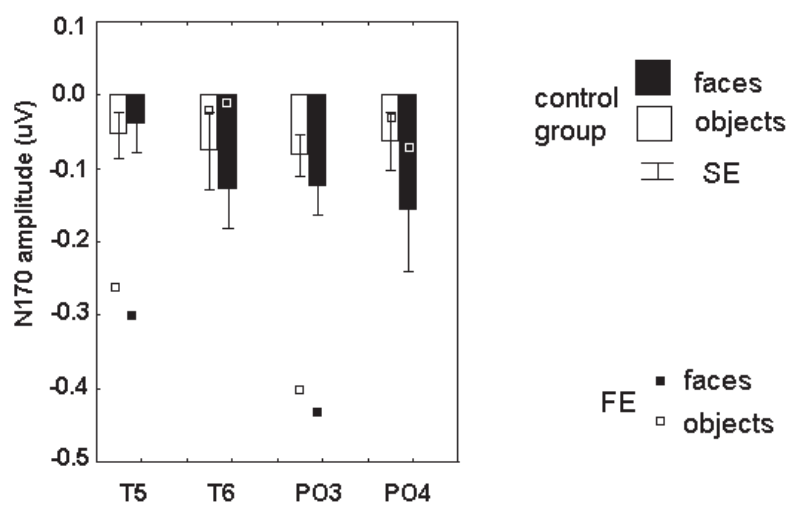

Figure 2. (A) ERPs triggered by faces (thick line) overlaid on those triggered by objects (thin line) at the T5 and T6 derivations referred to the average reference. On the left, the grand average ERPs from the control group, and on the right, the ERPs from patient FE. Results of permutation tests (contrasting amplitudes of faces and objects) are shown for each time point in an inset above the ERP with probability in a logarithmic scale. Dotted lines indicate the significant time regions. For the controls the difference in amplitude between average ERPs, related to faces and to objects, was tested over the group. In FE, the difference in amplitudes were tested over individual trials related to these stimuli. In this and subsequent figures, positive deflections point up. (B) Box plots with amplitudes values for N170 to faces and objects in the control group. Measures were taken as the mean values of the amplitudes in the time region between 130 and $230 \mathrm{~ms}$ in sites equivalents to derivations T5, T6 of the 10/20 system and PO3, PO4 of the 10/10 system. The same measures for FE are overlaid for each derivation. 
Statistical permutation analysis over the single trials in $\mathrm{FE}$ confirmed that this component was of larger amplitude for faces than for objects in the time window from about 175 to about $195 \mathrm{~ms}$. Therefore we assumed that this component is the N170. In contrast with the controls, the N170 component was systematically larger over the left hemisphere in FE. A comparison of the amplitude of N170 for FE and the normal controls is shown in Figure 2B. The amplitude of N170 was larger in FE than in the normal controls at T5 and PO3, and within the range of amplitudes corresponding to the controls at the right recording sites. The effect was significant at a time window between 130 and $230 \mathrm{~ms}$ in the modified $F$ test described in general methods.

The latency and posterior-temporal maxima of the N170 component found in FE was similar to the corresponding response from the age-matched control group of the present study, and to what has been described previously for other control groups (e.g., Bentin et al., 1996; Schweinberger et al., 2002). Nevertheless, it also presented some atypical features. The N170 in FE was larger over the left side of the scalp (in contrast to a larger amplitude over the right for normal controls) and had larger maximum amplitude than in the controls. These differences from the normal scalp distribution and amplitude are probably related to the extensive tissue destruction found on the ventral surface of the brain (see Figure 1). The scalp distributions may be altered ${ }^{2}$ by steep gradients of conductivity between intact and lesioned brain tissue (e.g., Huang, Nicholson, \& Okada, 1990), as well as by changes of skull conductivity due to fractures. (Patient FE did not suffer from skull fractures in his accident, but he was subsequently trepanned). The difference in topographic lateralisation may raise doubts as to whether it is the same component found in controls. However, the N170 in FE is face selective, as in the controls, which indicates a functional similarity.

The tissue damaged in FE (Figure 1) includes the sites on the fusiform gyri from which a facespecific N200 has been observed with intracranial recordings (Allison, Puce, Spencer, \& McCarthy, 1999; McCarthy, Puce, Belger, \& Allison, 1999; Puce, Allison, \& McCarthy, 1999), and also includes large part of the FFA identified by neuroimaging studies (Haxby, Horwitz, Ungerleider, Maisog, Pietrini, \& Grady, 1994; Kanwisher et al., 1997; Sergent, Ohta, \& MacDonald, 1992). The fact that in FE a large N170 was recorded, despite the destruction of the intracranial N200 recording sites, supports the idea that these are two different components.

These raise the question as to which cortical areas support the preserved face-structure processing and the N170 in FE. Candidates for this role are perhaps other regions related to face processing (Haxby, Hoffman, \& Gobbini, 2000), such as the lateral occipital face area (Halgren, Dale, Sereno, Tootell, Marinkovic, \& Rosen, 1999; Haxby, Ungerleider, Clark, Schouten, Hoffman, \& Martin, 1999) and the superior temporal gyrus (Hoffman \& Haxby, 2000; Puce, Allison, Bentin, Gore, \& McCarthy, 1998). Consistent with this, some studies have modelled dipole sources for N170 in the occipitotemporal sulcus (Bentin et al., 1996), or at lateral occipitotemporal sites (Schweinberger et al., 2002) outside the fusiform area. These more lateral sites did not appear to be damaged in FE.

\section{EXPERIMENT 2: P300 AND COVERT FACE RECOGNITION}

In a milestone study, Renault et al. (1989) examined the patient PC, affected by prosopagnosia, by presenting him with a randomly ordered sequence of unfamiliar faces and (more infrequent) familiar faces. The patient was asked to produce a familiarity decision on each face. Despite his failure to discriminate the stimuli overtly, a P300 component was of larger amplitude when elicited by the faces familiar in comparison to when it was elicited by the unfamiliar faces, indicating that covert recognition had occurred. The authors

\footnotetext{
${ }^{2}$ We thank S. Schweinberger for pointing out this possibility.
} 
proposed that the latency of the P300 was longer than in normal subjects, which they believed reflected a sluggish time course for the covert recognition in PC. This important result, which has not been replicated yet, raises several issues.

The first of these issues is that P300 really corresponds to a family of late positive components, each sensitive to different experimental factors, with divergent distributions over the scalp, and thus probably reflecting distinct mental operations (N. Squires, Squires, \& Hillyard, 1975). The parieto-central P300 (or P3b for short) is larger for informative trials (especially when something unexpected occurs) and is only generated when active attention is given to the stimuli (Picton, 1992; Ruchkin, Johnson, Canoune, Ritter, \& Hammer, 1990). The amplitude of P3b is directly related to the subject's confidence in his decisions (K. C. Squires, Hillyard, \& Lindsay, 1973). Although debated (see Donchin \& Coles, 1988; Verleger, 1988), an accepted interpretation is that $\mathrm{P} 3 \mathrm{~b}$ reflects the updating of working memory with respect to explicitly recognised stimuli. It is not clear how covert processing, in the absence of explicit recognition, could elicit a $\mathrm{P} 3 \mathrm{~b}$.

Frontally distributed components, such as the P3a (N. Squires et al., 1975) and the novelty P3 (Courchesne, Hillyard, \& Galambos, 1975) are considered to reflect more automatic and less attention-dependent processes than P3b (Escera, Alho, Winkler, \& Näätänen, 1998; Näätänen, 1992; Schroger, Giard, \& Wolff, 2000). One would suspect that this type of component could be activated in the wake of covert recognition. Unfortunately, since Renault et al. (1989) recorded from only a few electrodes, it is not possible to distinguish between the different types of P300 from the scalp distribution of their effect.

Another issue to consider is that Renault et al. (1989) did not report data from normal subjects using the same task and stimulus material used for their patient, and based their judgment of latency deviations on reported data obtained in somewhat different experiments. This is especially problematic for assessing the latency of P300, since this measure is very sensitive to task parameters (Picton, 1992). Hence comparison of $P 300$ latency between patients and normal controls should be based on the responses obtained with equivalent stimuli and experimental setups.

Here, following the method reported by Renault et al. (1989), infrequent faces of familiar people (the targets to be reported) were presented amidst more numerous faces of unfamiliar people with the aim of provoking a P300 component in FE and normal controls. For FE, faces of persons previously familiar to him (but who he was incapable of overtly identifying after the lesion) were used. The presence of a $\mathrm{P} 300$ component in $\mathrm{FE}$, triggered by these (once) familiar faces, would indicate covert recognition. However the present study differs from the previous report on several counts. First, high-density ERP recordings were employed to better characterise the scalp topography of the P300. Second, an age-matched control who shared the patient's familiarity with the stimulus set of faces (the patient's wife) was included as a control subject, permitting a fairer evaluation of the normality of P300 latency in FE. Third, the study was repeated twice, with a year between examinations, to assess the reliability of the findings. Last, an additional group of naive subjects also participated in order to control for the effects of any lowlevel pictorial cues in the photographs that could inadvertently have differentiated the familiar and unfamiliar faces.

\section{Methods}

$\mathrm{FE}$, control AE, and the naïve control group (described in General methods), participated in this experiment. AE was the patient's wife, a 60-year old healthy woman, without any history of neurological or psychiatric disease. Two sets of faces were used; one corresponding to photographs of 16 members of the patient's family taken before his accident (the target stimuli), and the other consisting of 84 faces completely unfamiliar to FE (the standard stimuli). The patient's wife, AE, easily recognised and named the 16 target pictures. She reported that FE was very familiar with the posers and was able to recognize all of them by their voices. All posers wore neutral expressions. The proportion of individuals from each sex, race, and 
age group were approximately matched in the two sets. FE was studied in two sessions (a year apart).

In the first session he was asked to perform a familiarity discrimination task with the face stimuli. The two types of faces (familiar and unfamiliar) were mixed into one set, and this set was presented twice, in a different random order for each pass. Therefore, a total of 32 familiar (16\%) and 168 unfamiliar (84\%) faces were presented, each for $1000 \mathrm{~ms}$, with an inter-stimulus interval (ISI) of $2500 \mathrm{~ms}$. FE was required to indicate the presence of a familiar face by pressing a key on the computer keyboard during the ISI (a go/no-go design). ERPs were recorded from 11 derivations of the 10/20 system (C3, C4, P3, P4, T5, T6, Fz, Cz, $\mathrm{Pz}, \mathrm{O} 1$, and O2) and two channels of EOG. The signals were amplified by a factor of 10,000 and filtered between $0.1-30 \mathrm{~Hz}$ ( $3 \mathrm{~dB}$ down).

In the second session, FE repeated the facefamiliarity discrimination task. However, in addition to different recording conditions (the 120 electrode montage was used, as explained in General methods), in this session responses were required for both "familiar" or "unfamiliar" faces (a go/go design) by pressing different keys on the computer keyboard during the ISI. The procedures of this second session were also used with the control subjects. These control subjects included AE because she was familiar with the posers for the familiar face photographs to the same degree as patient FE. Additionally the group of naïve subjects, unfamiliar with the faces (see earlier) was studied in order to control for any differences between familiar and unfamiliar faces unrelated to personal acquaintance.

\section{Results and discussion}

AE correctly classified the entire set of familiar faces $(100 \%$ correct), with only four mistakes with unfamiliar faces (2.4\% false alarms). In contrast, during both sessions $\mathrm{FE}$ classified all faces as unfamiliar ( $0 \%$ correct). None of the subjects from the naive control group recognised any face as familiar.

In the control recordings with the young subjects who were unfamiliar with the face stimuli, a P300 component was not observed. Tests examining differences between ERPs to the familiar and unfamiliar faces were not significant either in the omnibus test or at any time point, which indicates that a P300 effect with these stimuli can not be explained by confounds from pictorial cues independent from familiarity.

The grand average ERPs elicited at $\mathrm{Cz}$ by the familiar and unfamiliar faces for $\mathrm{AE}$ are overlaid in Figure 3. For control AE (Figure 3A) components earlier than $300 \mathrm{~ms}$ were similar in the ERPs elicited by familiar and unfamiliar faces. In contrast, the ERPs associated with the familiar faces presented an enhanced positivity that peaked at $520 \mathrm{~ms}$. This component, which corresponds to a P300, began at about $450 \mathrm{~ms}$ and was apparent until about 650 ms. The P300 was widely distributed over the head with maximal amplitude at centroparietal sites $(\mathrm{Cz}, \mathrm{Pz}, \mathrm{C} 4, \mathrm{P} 4$ of the $10 / 20$ system) and slightly larger over the right hemisphere. The P300 effect was tested statistically with the single trial data, using permutation techniques for dependent samples to compare ERPs associated with familiar and unfamiliar faces. In Figure $3 \mathrm{~A}$ the probability values obtained by the permutation test are shown for each time point in an inset above the ERP. The test was significant between 485 to $535 \mathrm{~ms}(p<.05)$, which corresponds with the timing of the peak in the recording.

We first describe results from the second session for $\mathrm{FE}$ (most comparable to those of AE). The early $\mathrm{ERP}$ components at $\mathrm{Cz}$ in $\mathrm{FE}$ were somewhat different from those of the control, but these responses were equivalent for familiar and unfamiliar faces (Figure 3B). At this site, ERPs elicited by the (unrecognised) familiar faces included a P300 with a latency of about $520 \mathrm{~ms}$, which was not present for unfamiliar faces. This P300 began at about $400 \mathrm{~ms}$ and lasted until about $640 \mathrm{~ms}$. This component was of lower amplitude and more restricted in topography than those described for $\mathrm{AE}$, showing the maximal amplitudes at central and frontal sites. The difference between ERPs elicited by familiar and unfamiliar faces was significant for the individual time points between 425 and $520 \mathrm{~ms}(p<$ $.05)$. This time window corresponds to the timing of the P3 in the recording (Figure 3B). 

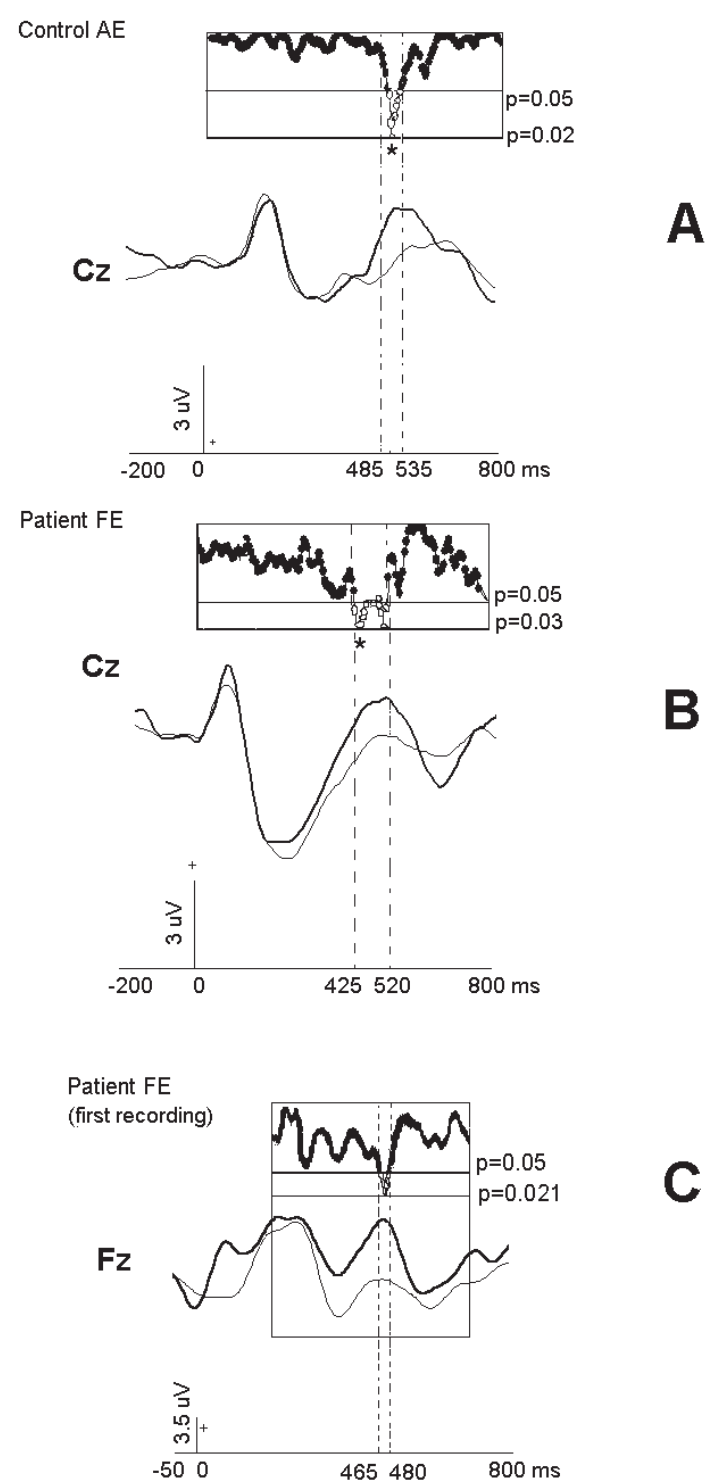

Figure 3. ERPs obtained during the discrimination of face familiarity. ERPs associated with unfamiliar faces (thin line) are overlaid on ERPs elicited by familiar faces (thick lines). Results of permutation tests based on individual trials are shown for each time point in an inset above the ERP with probability in a logarithmic scale. An asterisk marks the most significant time point. In the upper panel $(A)$ the recordings obtained from control $A E$, in the middle $(B)$ the recordings obtained from $F E$ in the second recording session, and in the lower panel $(C)$ the recordings obtained from $F E$ in the first recording session. Recordings in $(A)$ and $(B)$ correspond to $C z$ electrode referred to the average reference, and recordings in $(C)$ correspond to Fz referred to linked earlobes.
A positive component was also associated to infrequent familiar faces in the first recording taken from FE a year before (Figure 3C). This component was evident in several electrodes, but only reached significance at frontal sites. In $\mathrm{Fz}$, the difference was significant for the individual time points between $465-480 \mathrm{~ms}(p<.05)$. This window corresponds to the timing of the P300 in the recording (Figure $3 \mathrm{C}$ ), and is in the latency range obtained in the second study. These results were reproduced in two recordings, each separated by a 1 -year period. Some minor differences in timing and scalp topography of the P300 could be explained by the differences in the recording parameters between sessions.

No difference in peak latency was found between the P300 obtained with the same face stimuli in $\mathrm{FE}$ and $\mathrm{AE}$ (a control matched in age and degree of familiarity with the face stimuli). Permutation tests indicated that the P300 onset latencies, estimated as the first significant difference between ERPs elicited by familiar and unfamiliar faces, emerged at about $425 \mathrm{~ms}$ in patient $\mathrm{FE}$ and at about $485 \mathrm{~ms}$ in the control case AE. Therefore contact with face traces in memory was just as fast (or faster) in FE as in the control. Note that Renault et al. (1989) found a P300 peak latency of $700 \mathrm{~ms}$ in their patient PC. Comparison of this latency with normal P3 data from the literature (obtained in different tasks) led them to conclude that covert face recognition in $\mathrm{PC}$ was delayed respect to normal overt recognition. However, P3 latency varies widely as a function of stimulus material and task difficulty, consistent with the idea that it reflects stimulus evaluation time (Kutas, McCarthy, \& Donchin, 1977; Picton, 1992), and the mentioned comparison was perhaps not valid.

The topography of the P300 in AE and FE was examined by plotting the probability values for the difference between target and nontarget recording in each electrode (SPM, Figure 4). Visual inspection of these maps showed different scalp topographies of the $\mathrm{P} 3$ in $\mathrm{FE}$ and $\mathrm{AE}$ (Figures $4 \mathrm{~A}$ and 4B). The scalp distribution of the P3 (with a maximum at frontal sites) was more restricted in $\mathrm{FE}$ than in the control AE. Whereas the map in AE exhibited the typical widespread distribution with a 

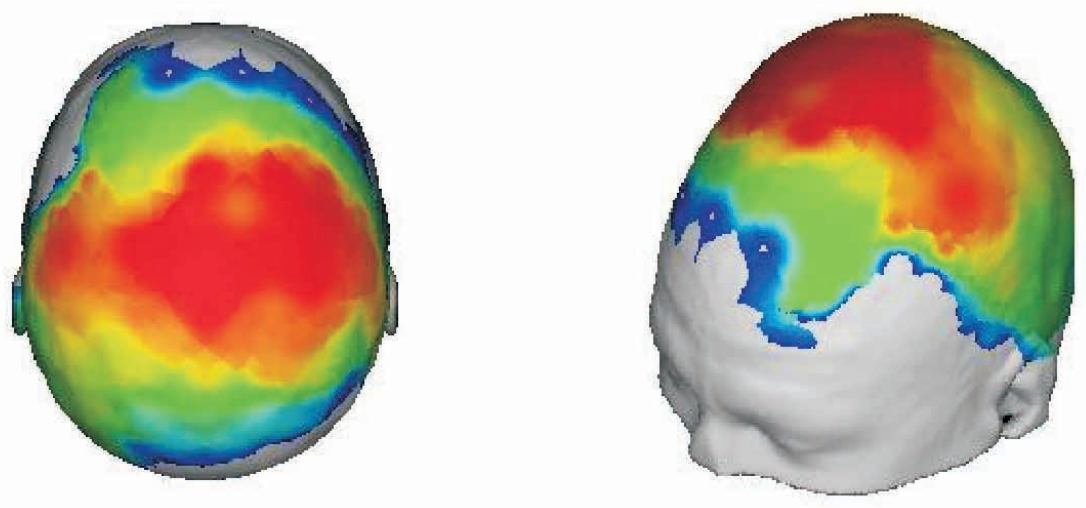

\section{A Control $\mathrm{AE}$}
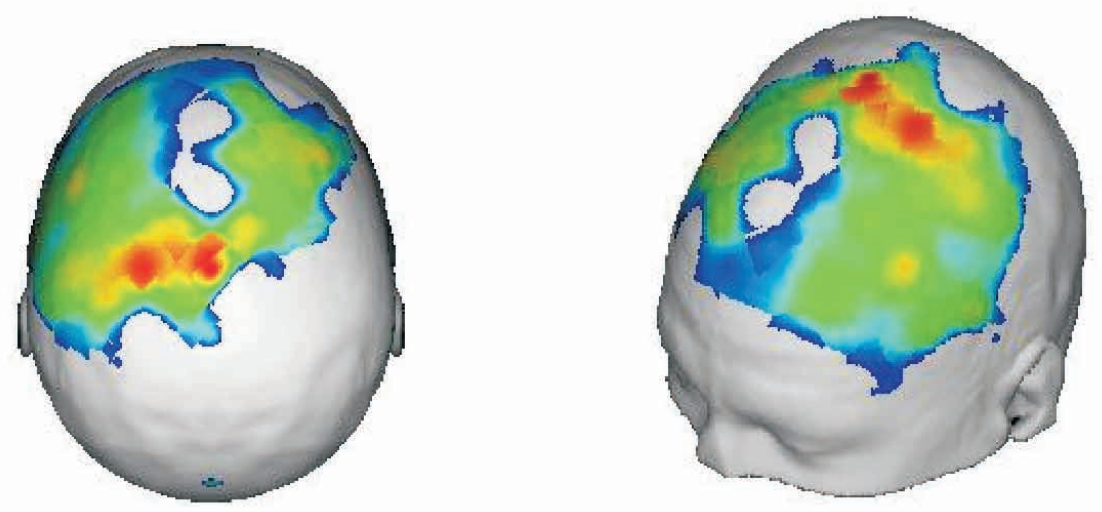

\section{B Patient FE}

Figure 4. Statistical parametric maps (SPM) representing the scalp distribution of the probability values from permutation tests in AE and FE. For each map the most significant time window was used (contrast of familiar vs. unfamiliar ERPs). (A) Map obtained in AE for the global analysis including all channels (omnibus test) from 470 to 550 ms. (B) Map obtained in FE for the omnibus test from 435 to $480 \mathrm{~ms}$ in the second session.

centro-parietal maximum corresponding to $\mathrm{P} 3 \mathrm{~b}$, in FE the largest amplitudes of P300 were found at fronto-central sites. This component was practically absent over the posterior part of the scalp, and in particular over the parietal regions, in $\mathrm{FE}$.

This distribution resembles that described for the P3a (cf. Comerchero \& Polich, 1999; Spencer, Dien, \& Donchin, 1999) and indicates that the P300 in the patient is not merely an attenuated version of the P300 found in the control. Frontal maximal components, such as P3a (N. Squires et al., 1975) and the novelty P3 (Courchesne et al.,
1975), are considered to reflect more automatic and less attention-dependent processes than P3b (Escera et al., 1998; Näätänen, 1992; Schroger et al., 2000). The P3a can be elicited even if the subject is not attending the stimulus, a manoeuver that has been used to isolate it from the P3b, which does requires active attention.

The divergent scalp topography of the P300 in $\mathrm{FE}$ and the control AE opens the possibility that the diverse neural sources (Picton, 1992; Rugg \& Coles, 1995) of this ERP component are activated to different degrees in the two subjects. A stronger 
(statistically based) test of this difference will be presented in Experiment 3. However, before concluding that this reflects the specific physiopathology of the prosopagnosia in FE, three alternative explanations must be excluded.

First, brain damage can alter the expression of electrical potentials at the scalp generated by the same neural sources, as discussed for Experiment 1. Could the frontal distribution of the P3 in FE be simply due to biophysical alterations subsequent to his brain injury? Second, local damage to a brain region could selectively affect a subset of the sources underlying an ERP component, thereby shifting its scalp distribution. Is the frontal distribution of the $\mathrm{P} 300$ in FE due to damaged generators located in the posterior cranium? Finally, FE responded to all faces pressing the same key. Given his frustrating failure to recognise faces, he may not even have tried to accomplish the task. Obviously this was not the case for the normal control, given her accurate performance. Could the difference in P300 components invoked in the two subjects be due to different degrees of attention to the face stimuli? The next experiment addressed these questions.

\section{EXPERIMENT 3: CONTRASTING THE P300 IN TASKS THAT REQUIRE AND DO NOT REQUIRE FACE FAMILIARITY}

In this experiment the primary task was the detection of infrequent inverted faces, interspersed among infrequent upright familiar faces and frequent upright unfamiliar faces. This design allowed us to address some of the concerns raised by the Experiment 2. First, the infrequent inverted faces would serve to elicit a P300 (measured against the baseline of the frequent upright unfamiliar faces) for a task easily performed by both FE (as ascertained in pilot tests) and controls. If the scalp distribution of the P300 elicited by familiar faces in Experiment 2 in $\mathrm{FE}$ was altered because of biophysical factors (i.e., variations in local conductivity, bone fracture, etc.), or by the loss of part of the P300 generator sources, then the topography of the P300 related to the inverted faces should also suffer the same deviation in the present experiment.

Second, since the primary task in the present experiment was to detect inverted faces, attention was drawn away from overt face identification for both $\mathrm{FE}$ and controls. Thus any face recognition present would be incidental for all the subjects, making the task used to produce a P300 related to familiarity more comparable among them. An additional goal of this experiment was to carry out a statistical comparison of the scalp topography of the P300 in FE and normal controls. There is considerable inter-individual variability in the topography of ERPs even in controls, which indicates caution when interpreting single case results. Therefore a group of five normal controls matched in age and education with FE were recorded.

\section{Methods}

The age-matched control group (described earlier) and FE participated in the experiment. The set of familiar faces for each subject in the control group included members of their respective families obtained from photograph albums. The same set of faces used in Experiment 1 was presented to FE, and the unfamiliar faces from that experiment were also used for the controls. Three different types of faces were randomly mixed in the stimulation set: 16 familiar faces, (familiar-face oddballs), 84 unfamiliar faces and 1 unfamiliar face presented upside down (inverted-face oddball). Both familiar and unfamiliar faces were presented twice, in a different random order for each pass, and the inverted face was repeated 32 times. Therefore, a total of 32 inverted (13.8\%), 32 familiar (13.8\%), and 168 unfamiliar (72.4\%) faces were presented, each for $1500 \mathrm{~ms}$, with an inter-stimulus interval (ISI) of $2500 \mathrm{~ms}$. Subjects were required to indicate the presence of an inverted face by pressing a key on the computer keyboard during the ISI (a go/no-go design). The recording procedure was carried out as explained for Experiment 1. ERPs were recorded from 19 derivations of the 10/20 international system and $\mathrm{Oz}$ and two channels of EOG; all electrodes were referred to an electrode located at the tip of the nose. For the statistical tests on the 
P300 components the difference waveforms were obtained by subtracting the ERPs related to standard unfamiliar faces from the ERPs related to oddballs.

\section{Results and discussion}

\section{Behaviour}

The performance of all subjects in the task, including FE, was highly accurate. Four of the five subjects from the control group detected $100 \%$ of the inverted oddball faces and the other subject only missed two inverted faces, reaching a performance of $94 \%$ correct. FE only missed one inverted oddball face, detecting $97 \%$ of the inverted faces. Thus the level of attention paid to the faces, and the general level of alertness, was well matched between $\mathrm{FE}$ and controls in this experiment.

\section{ERPs in the controls}

The grand average ERPs for the control group are depicted in Figure 5A, in which recordings related to the oddball stimuli are overlaid on those related to the standard stimuli. Two components were enhanced in the ERPs associated to invertedoddballs relative to those triggered by standards: An earlier negative wave at posterior sites (which was positive at frontal sites) that was identified as N200, and a later widespread positive peak (slightly larger at centro-parietal sites, and consistent with the P3b topography). The first component was significant in the permutation tests within two windows, one from $270 \mathrm{~ms}$ to $325 \mathrm{~ms}$, and the other from $410 \mathrm{~ms}$ to $430 \mathrm{~ms}$. The positive component lasted from about 430 to about $650 \mathrm{~ms}$. The effect was significant in the permutation tests (all $p<.03)$ at Fp2, F8, C3, C4, P3, T5, T6, and $\mathrm{Cz}$ within a time window between 485-640 ms. Importantly, this effect was present at posterior sites. The same analysis (based on single-trial EEG data) was significant for at least some time points within the 485-640 ms window in every individual subject (see Table 2).

The ERPs related to familiar-oddballs also contained two components that were enhanced relative to ERPs elicited by standards: A negative wave peaking at about $450 \mathrm{~ms}$ (larger over posterior sites), followed by a small positive wave peaking at about $630 \mathrm{~ms}$ (larger over frontal and central sites). However these effects were of smaller amplitude, and of longer latency, than the corresponding effects for the inverted-oddballs. The effect related to the negativity was not significant in the permutation tests. However, for the effect related to the

Table 2. Results obtained in permutation tests over the single trials (in a global analysis including all channels) in individual subjects, showing the presence of the P300 in Experiment 3

\begin{tabular}{|c|c|c|c|c|}
\hline \multirow[b]{2}{*}{ Case } & \multicolumn{2}{|r|}{ Inverted vs. unfamiliar faces } & \multicolumn{2}{|c|}{ Familiar vs. unfamiliar faces } \\
\hline & Time region & Electrodes & Time region & Electrodes \\
\hline Control 1 & $530 *-610$ & $\begin{array}{l}\mathrm{F} 3, \mathrm{~F} 4, \mathrm{C} 3, \mathrm{C} 4, \mathrm{P} 3, \mathrm{P} 4, \mathrm{~F} 8, \mathrm{O} 2, \mathrm{~T} 4, \mathrm{~T} 5, \mathrm{~T} 6, \mathrm{Fz}, \mathrm{Cz} \\
\mathrm{Pz}, \mathrm{Oz}\end{array}$ & $465^{*}-590$ & F8 \\
\hline Control 2 & $445^{*}-585$ & $\begin{array}{l}\text { Fp1, Fp2, F3, F4,C3, C4, P3,P4, F7, F8, O1 O2, T3, } \\
\text { T4, T5, T6, Fz, Cz, Pz, Oz }\end{array}$ & $560 *-575,655$ & $\mathrm{C} 3, \mathrm{~T} 4$ \\
\hline Control 3 & $400 *-620$ & $\begin{array}{l}\mathrm{Fp} 1, \mathrm{Fp} 2, \mathrm{~F} 3, \mathrm{~F} 4, \mathrm{C} 3, \mathrm{P} 3, \mathrm{P} 4, \mathrm{O} 1 \mathrm{O} 2, \mathrm{~T} 4, \mathrm{~T} 5, \mathrm{~T} 6, \mathrm{Fz} \\
\mathrm{Cz}, \mathrm{Pz}, \mathrm{Oz}\end{array}$ & $480^{*}-490$ & $\mathrm{~T} 6, \mathrm{Cz}$ \\
\hline Control 4 & $\begin{array}{c}550 *-585 \\
630-645\end{array}$ & $\mathrm{Fp} 1, \mathrm{~F} 3, \mathrm{~F} 4, \mathrm{C} 3, \mathrm{C} 4, \mathrm{Fz}, \mathrm{Cz}$ & $635^{*}-650$ & $\mathrm{C} 3, \mathrm{Fz}$ \\
\hline Control 5 & $555^{*}-585$ & $\mathrm{Fp} 2, \mathrm{~F} 3, \mathrm{~F} 4, \mathrm{~F} 8, \mathrm{Cz}, \mathrm{Oz}$ & - & - \\
\hline Patient FE & $530 *-645$ & F3, F4, C4, P3, P4, F7, F8, O2, T3, T4, T5, T6, Fz, Pz & $520^{*}-545$ & $\mathrm{~F} 4, \mathrm{Cz}$ \\
\hline
\end{tabular}

Time regions and electrodes that were significant are shown. The onset latency of P300 effect is marked with an asterisk (measured as the first time point at which a significant effect was found). 


\section{A}

Control group
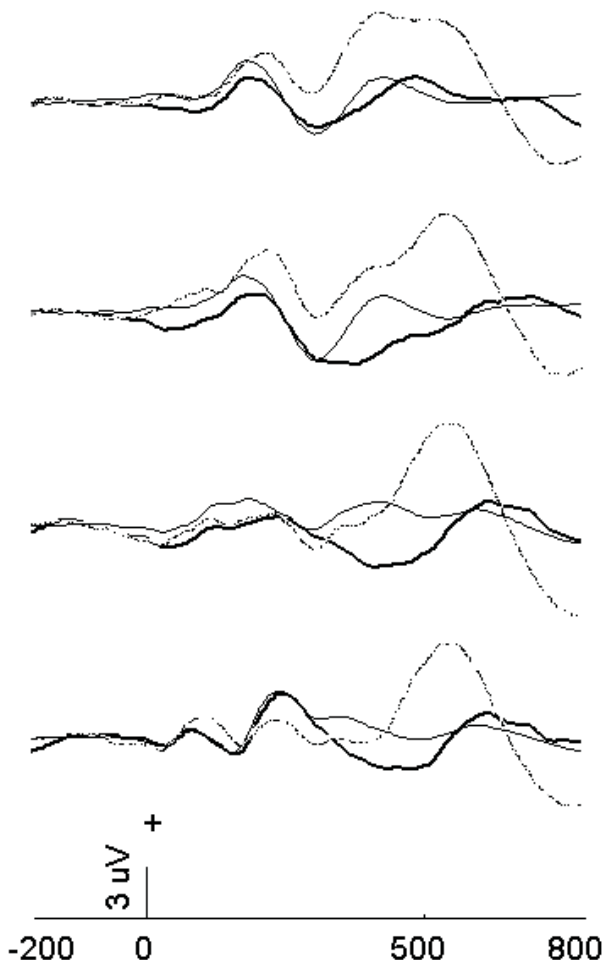

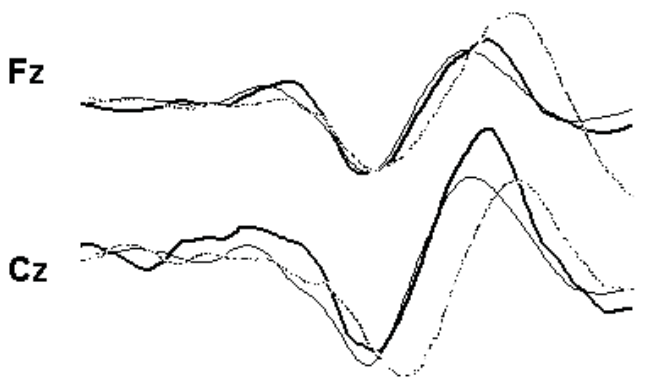

$\mathrm{Pz}$

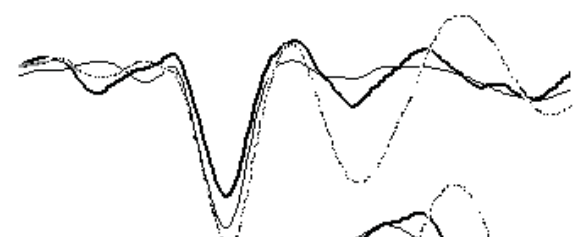

$\mathrm{Oz}$

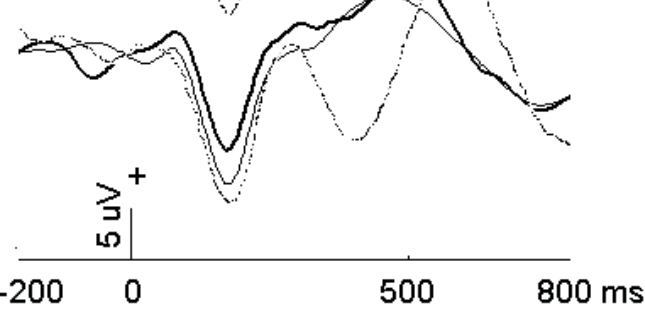

\section{_ frequent unfamiliar faces \\ _ infrequent familiar faces \\ _ n in.m.n.m infrequent inverted target faces}

Figure 5. Overlay of ERPs waveforms obtained for frequent unfamiliar faces (black thin line), familiar oddball faces (black thick line) and inverted oddball faces (dotted line). (A) In the left panel, grand averaged ERPs of the control group. (B) In the right panel the ERPs from $F E$. Recordings were taken from midline electrodes, referred to the tip of the nose.

positive peak the permutation tests were significant $(p<.04)$ for two narrow time regions $(460-475 \mathrm{~ms}$ and 500-515 ms) at Fp1, F3, and Fz. Inspection of the ERPs for individual subjects revealed a large variability in this positive wave (Figure 6). The effect was clearly observable in three of the five subjects, although significant effects $(p<.03)$ were found in four subjects with the permutation tests. These effects were located in a narrow time region for each subject, which varied between subjects in onset, duration, and electrode location (see Table 2).

\section{ERPs in FE}

The ERPs obtained for $\mathrm{FE}$ in this experiment are depicted in Figure 5B. Large differences were found between the responses to both types of oddballs and the responses to standards. In the ERPs related to inverted-oddballs, FE exhibited a large negative wave (N200) that was significant in the permutation tests at many electrodes $(\mathrm{C} 3, \mathrm{C} 4$, P3, P4, O1, O2, T3, T4, T5, T6, Cz, Pz, and Oz) for the time window from $365 \mathrm{~ms}$ to $470 \mathrm{~ms}$. This effect was followed by a prominent positivity (P3b) 


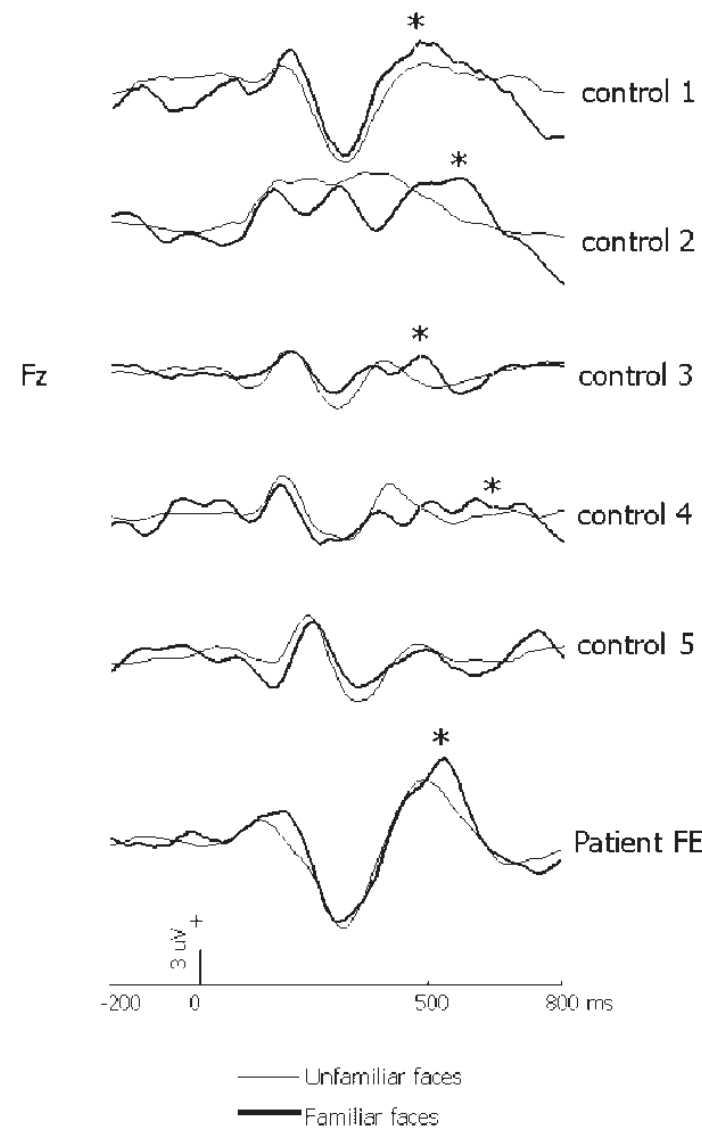

Figure 6. ERPs waveforms obtained for frequent unfamiliar faces (thin line) and familiar oddball faces (thick line) in each control subject and patient FE. Recordings were taken from $F z$ electrode, referred to the tip of the nose. An asterisk indicates the first latency at which the P300 effect was significant in the cases where this happened. The recordings of the control subjects are presented in the same order as for Table 2.

with a latency of about 533 to $680 \mathrm{~ms}$, that was widely spread over the scalp, but with a maximum at central and parietal sites. This P3b component was significant in the permutation tests for channels $\mathrm{F} 3$, F4, F7, F8, T3, T4, C4, T5, T6, P3, P4, O2, Fz, and $\mathrm{Pz}$ in a time region between 530 and $645 \mathrm{~ms}$ $(p<.001)$.

This topography is similar to the homologous response in controls, and importantly with significant effects at posterior sites. Figure 7A depicts a comparison between the scalp topography of $\mathrm{P} 3 \mathrm{~b}$ in $\mathrm{FE}$ and the control group at midline sites, showing that the amplitudes of this component in $\mathrm{FE}$ were comparable to normal controls for all midline sites (similar results were obtained for the left and right derivations). The mean of $\mathrm{P} 3 \mathrm{~b}$ amplitude within the time window from 520 to $620 \mathrm{~ms}$ did not differ significantly between $\mathrm{FE}$ and the control group at any of the recording sites (using the modified $F$ test described in general methods). The onset latency of the $\mathrm{P} 3 \mathrm{~b}$ effect in $\mathrm{FE}$ is also comparable with that of normal controls (see Table 2).

A P300 associated to familiar faces was clearly observed in FE, and was larger than the corresponding peak in the grand average of the control group (Figure 5B), although similar to the effect in some of the individual subjects (see Figure 6). This P300 had an onset at about $477 \mathrm{~ms}$, and lasted until about $600 \mathrm{~ms}$, with a peak at about $534 \mathrm{~ms}$, with larger amplitudes at frontal and central sites. Permutation tests on the single-trial EEG data in $\mathrm{FE}$ evinced a significant P300 effect between 520 and $545 \mathrm{~ms}$ (all $p<.03$ ) at $\mathrm{F} 4$ and $\mathrm{Cz}$ sites.

The scalp distribution of the P300 associated with familiar-oddballs in both $\mathrm{FE}$ and controls was clearly different from the distribution of the P3b obtained with inverted-oddballs (see Figure 7). The P300 associated with familiar-oddballs was significant only in anterior regions whereas the P3b related to inverted-oddballs was also present at posterior sites. Note that the relative amplitude of the familiar oddball-P300 at $\mathrm{Cz}$ is somewhat larger for $\mathrm{FE}$ than for the control group (see Figure 7B). However, before and after normalisation across electrodes, the mean amplitude from 500 to $600 \mathrm{~ms}$ of the P300 related to familiar oddballs was not significantly different between $\mathrm{FE}$ and the control group at any of the recording sites. Due to the inconsistent topography of this component in the controls, these conclusions must be regarded with caution. Importantly, the (normalised) mean amplitude of the P300 related to familiar oddballs in FE was significantly different from corresponding values for the $\mathrm{P} 3 \mathrm{~b}$ related to inverted oddballs in the controls at two electrodes (T5 and T6, $p<.05$ with the modified $F$ test). The onset latency of the $\mathrm{P} 300$ in $\mathrm{FE}$ was in the same time range as that obtained for this patient and for control AE in the previous experiment (Table 2). 


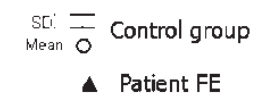

A
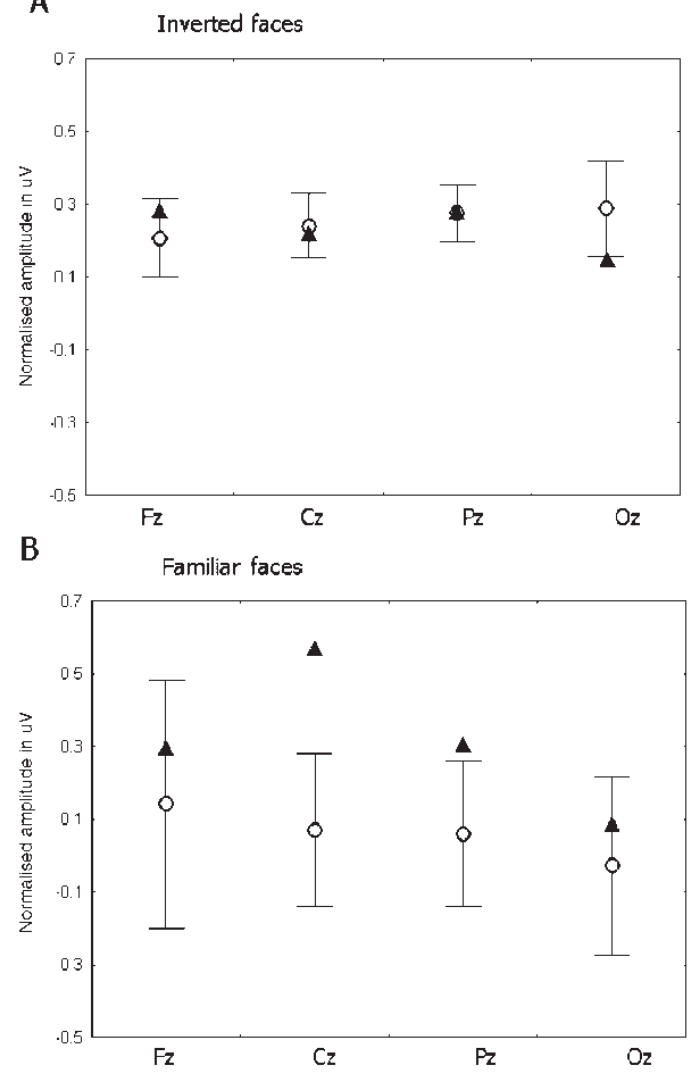

C

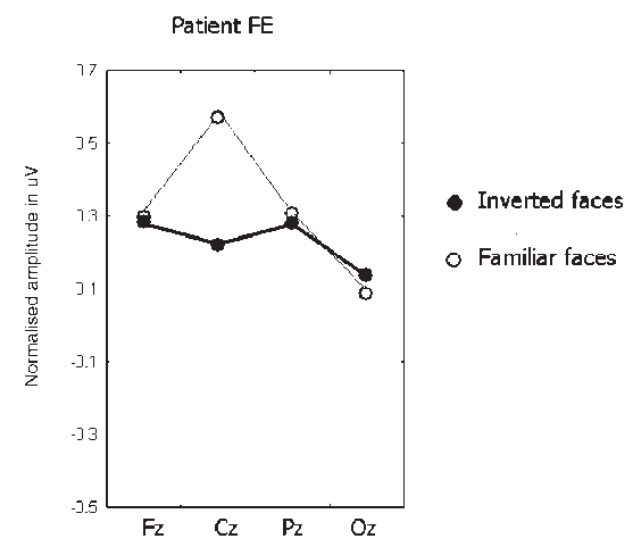

Figure 7 (left). Mean and standard deviation of the normalised amplitude values of the infrequent recordings for the control group in a time window including the P300 component. The same values for FE are overlaid in darkest triangles. (A) In the upper panel, values for the $P 300$ obtained to inverted faces in the time window between 520 and 620 ms. (B) In the middle panel, the P30O obtained for familiar faces in the time window between 500 and $600 \mathrm{~ms}$. (C) In the bottom panel, amplitude values of the P30O obtained in FE for infrequent inverted faces (dark circles) and infrequent familiar faces (white circles) in the same time windows described before.

The results of this experiment demonstrate that $\mathrm{FE}$ and the normal controls both exhibit a P3b triggered by the inverted-oddball stimuli. The topography and latency of this P3b did not differ significantly between $\mathrm{FE}$ and the controls. An N200 preceding the P300 was also found both in the controls and in FE (in whom this response was very large). The N200 (Hillyard \& Picton, 1987) is a distinct component that almost invariably accompanies the P3b. This pattern of results precludes the possibility that the deviant topography of the P300 found in Experiment 1 for $\mathrm{FE}$ is due to partial damage to the neural generators of the component, or to abnormal intracranial biophysical properties.

A significant $\mathrm{P} 300$ effect related to familiar faces was found in FE. This was the third replication of the effect over several years. However, the P300 associated to familiar face oddballs was not large or reliable in the control group. Several factors could have contributed to this result. Since the stimuli were tailored for each individual (originating from different family albums) they may not have been completely matched in degree of familiarity. Also, the processing of familiarity was incidental in the task and the amount of attention dedicated to this attribute may have varied among control subjects. Therefore although the data suggests that the topography of the P300 related to familiar oddballs differs from that of the $\mathrm{P} 3 \mathrm{~b}$ related to inverted faces within the controls, and also differs from the topography in $\mathrm{FE}$, these results must be confirmed in further experiments.

Outstandingly, the scalp topography of the frontal P300 elicited by covert face-familiarity in FE (demonstrated in Experiments 2 and 3) is 
different from that of the P3b related to faceinversion oddballs, which in both $\mathrm{FE}$ and controls has a centro-parietal maximum. Moreover, in FE the large N200 component associated with the P3b was absent for the response triggered by familiar face oddballs. These results support the idea that the P300 elicited by covert recognition of faces in $\mathrm{FE}$ is a different component from the classical P3b generated by explicit recognition of stimulus deviance.

\section{EXPERIMENT 4: SCR AND COVERT AFFECTIVE PROCESSING IN FE}

To further characterise residual face processing in $\mathrm{FE}$, two measures of covert face recognition that had been previously reported in the literature were examined. One was the SCR, which has been reported to be larger for familiar faces than for unfamiliar faces in some cases of prosopagnosia (Bauer, 1984; Tranel \& Damasio, 1985) although not in others (Etcoff et al., 1991; see Bruyer, 1991). Additionally a forced-choice face selection test was used. This type of test has revealed covert familiarity in some cases of prosopagnosia (Barton, Cherkasova, \& O'Connor, 2001), although not in other cases (Barton et al., 2001; Diamond, Valentine, Mayes, \& Sandel, 1994).

A study by Greve and Bauer (1990) influenced our selection of forced-choice tests. In their study a patient with prosopagnosia was briefly exposed to a group of faces and when subsequently presented with a pair of faces (one old and one new) was required to select one of the two as either the most familiar or the most likeable (knowing vs. liking). The patient liked the previously encountered faces more, although he was not successful in explicitly classifying them as old. If this procedure uncovered covert recognition in prosopagnosia after only a brief exposure, it should be also successful for emotionally significant and overlearned faces of close relatives. Implicit recognition of this type was also demonstrated by Stone, Valentine, and Davis (2001) in normal subjects, who classified famous faces as "good" or "evil" with accuracy above chance even though these faces were pre-and post-masked to avoid conscious recognition.

Since familiarity is not an "all or none" phenomenon, we first asked $\mathrm{FE}$ to rate the degree of acquaintance and emotional ties to the posers for the face stimuli. The learning and emotional significance of another person's face should be directly related to the intensity of the interpersonal relationship established with that person. These ratings allowed us to examine in FE the relationship between SCR amplitudes (and the P300 amplitude obtained in previous experiments) with the degree of person-familiarity with the posers for the faces stimuli.

\section{Methods}

Before the experiments, FE was asked to rate the set of face stimuli with a 6-point scale of familiarity, as described by Tranel and Damasio (1988). He classified all faces as "completely unfamiliar". The names of the posers were also read out to FE, and he was asked to rate the degree of familiarity for each person with a 6-point Likert scale ranging from " $a$ totally unfamiliar person" to "a very familiar person." A similar rating was obtained about the type of emotional response elicited by each poser using a 5point scale ranging from "very unpleasant" to "very pleasant."

FE participated in two experimental sessions. In the first session FE was presented with two face photographs showed side by side on the screen, one of which was of a close relative with high personfamiliarity rating whereas the other was of a stranger. A total of 14 pairs were used. Each face subtended a vertical visual angle of about 1.3 degrees and an horizontal visual angle of about 0.6 degrees, and were presented until the subject indicated his response by pressing a key on the computer keyboard. The familiar face was randomly placed on the right on half of the trials. Four randomly ordered runs were performed through the series of pairs. On the first, he was asked to pick out one face on the basis of which was most trustworthy. On the second run he was asked to select the person he could confidently recognise. On the third run he was asked to select the person 
that seemed nicer. On the last run he was asked to pick out the face that seemed less unfamiliar (he was instructed to select the face that could correspond to an acquaintance). The same material and procedures was used with 20 control subjects completely unfamiliar with posers.

In the second session, SCRs were measured using an adaptation of the methods reported in Tranel and Damasio (1988; Experiment 1). The stimuli consisted of 52 faces, 13 of which FE was personally acquainted with before his accident (familiar faces), and 39 of which were unknown to him (unfamiliar). The photographs used as stimuli consisted of frontal views, and were roughly equivalent in size and contrast. Each face was displayed within a circular border, which masked the external features, clothes, and background. The stimuli were presented on a VGA monitor and subtended a vertical visual angle of about 2.9 degrees and a horizontal visual angle of about 1.2 degrees. Familiar and unfamiliar faces were randomly interspersed.

Each stimulus was presented during $2 \mathrm{~s}$, and the next stimulus was delayed until the SCR recording related to the previous one had returned to baseline. This resulted in inter-stimulus intervals longer than 20 s. FE was instructed to passively view the faces.

Electrodermal activity was recorded by using $\mathrm{Ag} / \mathrm{AgCl}$ electrodes taped to the palmar surface of the proximal phalanx of left index and middle fingers after cleaning the attachment sites and applying conductive gel, and the signal was fed via a skin conductance-processing unit (GSR-2100, Nihon Kohden, Japan) to a channel of the MEDICID III/E system. The filtered analogue output of the SCR was displayed online and recorded digitally (sample rate, $100 \mathrm{~Hz}$ ), in synchronism with the onset of the face, using custom-made software. The first trial after a familiar face and those presenting artifacts were rejected. The data were detrended and temporally smoothed (gaussian kernel with full-width at half maximum of $2000 \mathrm{msec}$ ) offline. SCR was measured as the largest peak in a time window of 10 $s$ after the stimulus onset, and only those responses with their initial deflection within $5 \mathrm{~s}$ after the stimulus were used. This value was then subtracted from the baseline signal (defined as the mean value in the 1 second before the stimulus). SCR amplitudes are reported as the proportion of the largest response within each subject.

The amplitude of the P300 related to familiar face oddballs in FE (from Experiments 1, 2, and 3) was measured in the single trial EEG epochs. Electrode $\mathrm{C} z$ was used for this because it presented the largest responses. All of the artifact-free EEG epochs corresponding to a familiar face were submitted to zero-phase shift low pass digital filtering $(3 \mathrm{~dB}$ at $5 \mathrm{~Hz})$. The mean amplitude of each epoch was measured for the time window from 474 to $635 \mathrm{~ms}$, and the mean amplitude of a $200 \mathrm{~ms}$ pre-stimulus window was subtracted from this value.

\section{Results and discussion}

When presented with the names, FE rated most of the posers for known faces as familiar or very familiar. They were also described as emotionally close (agreeable) to FE. All of these were family members (wife, sons, grandsons, etc). Four people were rated as relatively unfamiliar or only slightly familiar, and three people were emotionally neutral to FE (all of these posers were family friends).

FE picked out the familiar face on 10 out of 14 trials when asked to select on the basis of trustworthiness $(71 \%)$, which is significantly above chance, $\chi^{2}(1)=4.86, p<.028$, and on 8 out of 14 trials when asked to select the person he could identify with confidence (57\%), which is not significantly above chance $(p>.28)$. When asked to pick out a face on the basis of which of the two belonged to an acquaintance, he selected the familiar face on 12 out of 14 trials (86\%), which is highly significantly above chance, $\chi^{2}(1)=7.1, p<.008$. When asked to select the nicest face he selected the familiar face 9 out of 14 times (64\%), which was not significantly above chance $(p>.2)$. Note that when debriefed FE stated that he had responded to this task by chance and that none of the faces elicited a subjective feeling of familiarity. The control subjects, equally unfamiliar with both sets of faces, performed at chance in all the tasks. This excludes the possibility of preferential selection based on pictorial cues or innate attractiveness of the faces. 
In a first analysis of the SCR including all faces, the difference in amplitude between SCRs related to familiar and unfamiliar faces just missed significance. A subsequent analysis included only the faces of people who received high ratings in the Likert scale for familiarity. The mean amplitudes for the SCRs related to the faces of these very familiar people vs. the unfamiliar faces are shown in Figure 8 . The mean amplitude of the SCR for the unfamiliar faces was 0.21 , about $48 \%$ of the same measure for very familiar people, which was 0.41 . This difference was significant in a Mann-Whitney $U$ test, $U(7,17)=25, p<.028$. If all the familiar faces were included, the amplitude of the SCRs to familiar faces was highly correlated with the Likert ratings of emotional significance reported by $\mathrm{FE}$, Spearman $R=0.79, t(9)=3.88, p<.004$.

The amplitude of the individual P300 epochs was larger for the faces with higher personfamiliarity ratings. The Spearman correlation coefficient between the P300 amplitude estimate for each face and its Likert rating for personfamiliarity was calculated separately for each of the recording sessions (experiments) to avoid unwanted variance due to differences in recording conditions. The three correlations were significant:

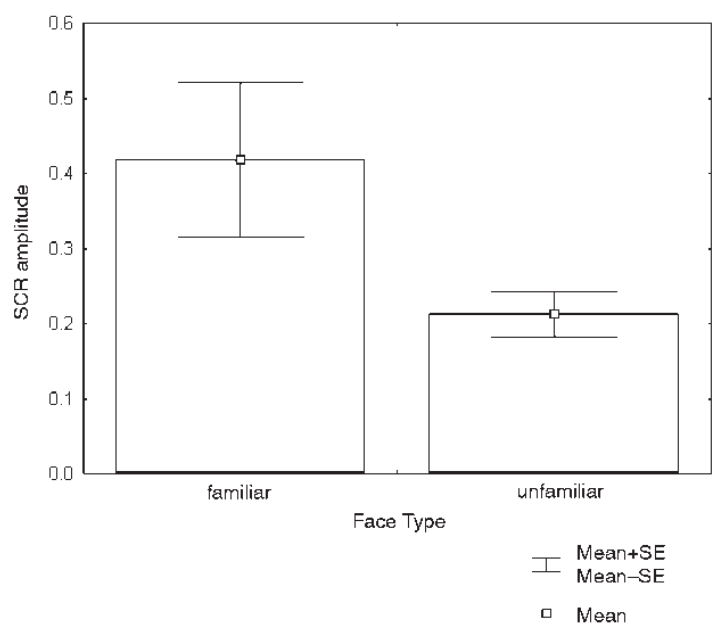

Figure 8. Mean skin conductance response (and standard error) in FE for familiar and unfamiliar faces. The amplitudes are expressed as proportions of the maximum response.
$R=0.46, t(26)=2.7, p<.013 ; R=0.52, t(16)=2.45$, $p<.026 ; R=0.52, t(22)=2.8, p<.01$. The corresponding correlations of $\mathrm{P} 300$ amplitude with the Likert ratings for emotional ties were also significant in the second session of Experiment 2 and in Experiment 3, but not for the first session of Experiment 2.

The outcome of the forced-choice test depended critically on how the question was posed. When judging on the basis of trustworthiness, or possible familiarity, the faces of close personal acquaintances were selected significantly above chance. When asked to select the nicest face, there was a nonsignificant trend to select the previously experienced face. When asked to select the face that could be recognised with confidence, behaviour was at chance. The procedure and results of Greve and Bauer (1990) were thus extended to the case of faces with high emotional significance for the patient. Our results are also in accord with De Haan et al. (1992), who report that NR, a patient with prosopagnosia, selected a subset of famous faces when these were paired with unfamiliar faces in a forced-choice task. However, NR had no subjective sense of familiarity.

The results of this experiment are in accord with findings from previous studies of the SCR in some cases of prosopagnosia. Larger SCRs are obtained to familiar than to unfamiliar faces in FE. However, the amplitude of the SCR was not equivalent for all familiar faces. A significant difference with the unfamiliar faces emerged only when SCRs related to faces of people that $\mathrm{FE}$ reported as close and emotionally significant were classified as familiar. Interestingly, the P300 related to familiar face oddballs also seems to be larger for people who were socially and emotionally closer to FE. The fact that both responses are correlated with the same variable opens the possibility that the neural pathways generating SCR and P300 share some common stages, and that both reflect the processing of affective or social cues. Among the neural structures involved in the processing of this type of information are the STS, the amygdala, and ventromedial frontal cortex (Breen et al., 2000).

This conjunction of results brings to mind the somatic marker theory (Tranel, Bechara, \& Damasio, 
2000), in which specialised brain structures establish permanent connections between complex (socially relevant) stimuli and internal states of the organism such as emotions. The somatic markers are thought to unconsciously influence decisionmaking. The behaviour of individuals with lesions to ventromedial frontal cortex is the motivation for this theory. Despite adequate intellectual functioning they make poor vital decisions, and are unable to regulate their actions in a socially appropriate manner. This is accompanied by reduced SCR to emotionally significant stimuli, and in situations simulating risky "gambling" decisions (Tranel et al., 2000) in contrast to normal controls.

Tranel et al. (1995) have argued that ventromedial frontal patients (with little SCR reactivity to familiar faces) and prosopagnosic patients (with adequate SCR reactivity to familiar faces) constitute the double dissociation necessary to identify two separate systems, one for factual nonsomatic information and the other a somatic valence-based system. The idea that somatic markers can influence decisions independently from explicit familiarity knowledge is congruent with the results from the agreeability or trustworthiness decision tasks presented here.

\section{GENERAL DISCUSSION}

Here, ERPs were employed to characterise the residual face processing of $\mathrm{FE}$, a patient with a dense prosopagnosia subsequent to extensive damage to the ventral temporal-occipital regions, including the fusiform gyri in both hemispheres. A large (face-specific) N170 was present in FE and he performed well in tests tapping face structural processing. Also, on three separate occasions, covert recognition of the faces of personal acquaintances was demonstrated with P300 oddball experiments. This P300 was not preceded by an N200. The onset latency of the P300 effect was equivalent to similar components in normal controls, demonstrating that the time course over which the face memories were available for covert recognition was not sluggish, nor tardy. However, the topography of this component in $\mathrm{FE}$ was different from that the $\mathrm{P} 3 \mathrm{~b}$. The recording of a normal $\mathrm{P} 3 \mathrm{~b}$ in $\mathrm{FE}$ in a different oddball face inversion task excludes the possibility that this topographic change was due to biophysical changes or the loss of neural generators.

FE performed at chance when asked to select between the face of a familiar person and that of an unfamiliar person on the basis of explicit recognition, whereas if selection was based on trustworthiness or a vague sense of familiarity, he selected the face of familiar people significantly above chance. The SCRs elicited by faces in FE were larger for familiar than unfamiliar faces. The amplitudes of both the single-trial P300s and the SCRs triggered by familiar faces were positively correlated with the degree of person-familiarity that FE had for the poser.

These results provide clues about the damaged and residual neural mechanisms related to face processing in FE, and can inform models of face processing. The large amplitude of the face-specific N170 in FE indicates that this component can be elicited without explicit recognition of faces. This is congruent with a lack of sensitivity of N170 to the familiarity of the eliciting faces (Bentin \& Deouell, 2000; Eimer, 2000a, 2000b; Rossion et al., 1999; Schweinberger et al., 2002) or to repetition priming (Schweinberger et al., 2002) in normal controls. These facts indicate that N170 indexes early stages of face processing prior to contact with the FRUs. These early stages would support the preserved structural face processing abilities in FE (as indexed by the CTBFP battery) and could be a first step in a chain leading to covert recognition of familiar faces in this case.

When compared to equivalent control data, the onset and peak latency of the P300 related to familiar faces in FE is within normal range. Note that this type of comparison is more difficult with slow physiological responses like the SCR. This result is somewhat unexpected, if we assume that FE's prosopagnosia originates in a dysfunction of an early "visual" stage of face processing. Dysfunction of this type usually affects speed of perception in addition to accuracy (Farah, 1990). This type of dysfunction has been simulated in computer 
models like that of Farah et al. (1993) by partially damaging the face input (or hidden-face) units. These simulated lesions would produce an increased number of cycles for the model to settle (see Figure 5 in Farah et al., 1993, and Figure 4 in O'Reilly \& Farah, 1999), which would translate into abnormally prolonged times for the execution of face processing tasks (including those with unfamiliar faces). Evidence in line with these conclusions was obtained in an experiment in which FE performed a face identity-matching task (Bobes et al., 2003). Unfamiliar faces were sequentially presented and FE was asked to judge if they represented the same person or not, a task that he was unable to perform overtly. In contrast, the ERPs related to repeated (matching) faces differed from those related to nonrepeated (mismatching) faces. The timing of this covert sign of successful matching corresponded to the lower limit of latencies for normal controls (see Schweinberger \& Burton, 2003, for discussion of this experiment).

The same issue can be examined within the framework of the computational model of face processing described by Burton et al. (1991). Prosopagnosia is simulated in this model by weakening the connections between FRUs and PINs (Young \& Burton, 1999). Normal latencies of the frontal-P3 would be expected for this simulation if this ERP component arises subsequent to activation of the FRUs (therefore explaining the covert recognition), but generated within a route parallel to the PINs, as proposed in the model of Breen et al. (2000).

Another important issue is the nature of the P300 elicited by covert face recognition in FE. Distinctions explicitly recognised by FE (inverted vs. upright faces) can elicit a classical N200/ (parieto-central) P3b complex in this patient, which is in accord with the idea that this complex reflects the updating of working memory with explicitly perceived information. The lack of a clear N200, and the more frontal distribution of the P300 elicited by familiar (but not explicitly recognised) faces indicates the activity of a different processing route. It is interesting that several reports exist of $\mathrm{P} 300$ components triggered by stimuli not consciously perceived, such as subthreshold stimuli in visual oddball paradigms (Bernat, Shevrin, \& Snodgrass, 2001; Brazdil, Rektor, Daniel, Dufek, \& Jurak, 2001; Devrim, Demiralp, \& Kurt, 1997). In several of these studies, differences in latency, amplitude, and topography were reported with respect to the classical P3b related to supra-threshold stimuli in the same experiment. This is congruent with the findings for FE; although he was aware that the stimuli were faces, he was not consciously aware of the critical distinction (familiarity) triggering the P3.

In the present study, the faces of relatives of the patient and control were used as the infrequent stimuli, and were therefore emotionally salient to them. This was evinced by enhanced SCRs in FE, a finding that replicates previous studies of SCR in prosopagnosia (Bauer, 1984; Tranel \& Damasio, 1985). Here, both SCR and P300 amplitude are positively correlated with a rating of the emotional significance of the persons who faces were used as stimuli. This suggests that a common process is involved in generating the two physiological responses. Consistent with this, a recent study found a correlation between the P3a amplitude and the intensity of skin sympathetic nerve activity (Ito, Sugiyama, Mamo, Okada, Matsukawa, \& Iwase, 1996), hence suggesting a link between the two physiological measures. Therefore, we hypothesise that part of the processing route producing the SCR also feeds into the neural generators of the frontal-P300 elicited by familiar faces in FE. This route should not depend on the two FFAs, which were both severely damaged in FE.

This hypothesis can be made more precise in relation to the update of the Bruce and Young (1986) model of face processing presented recently by Breen et al. (2000; see also Ellis \& Lewis, 2001). In the model there are two routes that follow from the FRUs. One route leads to the personal identity nodes (PINs) and is necessary for overt recognition. Familiarity would result from the activation of the PINs. The other leads to a parallel system that evaluates affective responses and can activate the SCR. Prosopagnosia would result from either partial damage to the FRUs, or a weakening of the connections between the FRUs and the PINs. 
We propose that the frontal-P3 (in contrast to $\mathrm{P} 3 \mathrm{~b}$ ) is downstream from the same affective evaluation system that leads to the SCR (see Figure 4 in Breen et al., 2000). This would be consistent with the evidence discussed above on preserved early face processing and short latencies for the P300 related to familiar faces. In the proposal by Breen et al. (2000) there is an input to the PINs from the affective system, which creates an indirect link between the FRUs and the PINs. This link could be responsible for the weak and vague sense of familiarity that FE evinced in the forced-choice task. Note that different types of covert processing can be envisioned within this scheme (i.e., semantic-based or affective), and this seems to be supported by the literature reviewed above (see Schweinberger \& Burton, 2003, for a discussion of this idea).

Furthermore, the data prompt us to speculate that one structure participating in this affective evaluation system is the ventromedial prefrontal cortex and perhaps the anterior cingulate. Several studies link both the SCR and the frontally distributed P3a to this cortical region. Whereas both P3a and $\mathrm{P} 3 \mathrm{~b}$ are reduced in patients with temporoparietal junction damage, only $\mathrm{P} 3 \mathrm{a}$ is affected in patients with prefrontal lesions (reviewed by Knight \& Grabowecky, 1995). Moreover, sources for the P3a have been reported in the anterior cingulate and orbitofrontal cortices by two groups (Baudena, Halgren, Heit, \& Clarke, 1995; Brazdil, Rektor, Dufek, Daniel, Jurak, \& Kuba, 1999) using intra-cranial electrodes. On the other hand, damage to ventromedial prefrontal areas diminishes SCRs to emotionally arousing stimuli (Zhan, Grafman, \& Tranel, 1999), and fMRI activation within the same areas has been found to be correlated with SCR amplitude (Critchley, Elliot, Mathias, \& Dolan, 2000).

The ventromedial prefrontal area is seen as part of the somatic marker system (Tranel et al., 2000), discussed in Experiment 4. Perhaps the SCR, and the P300 (and the P3a found in other studies) all reflect activation of this system underlying somatic markers. The finding that FE selected the faces of close relatives more frequently when faced with a forced choice based on affective criteria (trustworthiness and likeability), despite failures of overt recognition, supports this hypothesis.

To conclude, the ERPs data suggest that despite extensive damage to both fusiform gyri, early face processing was relatively intact in FE. The same data also suggest that covert activation of memories for familiar faces is possible and fast. The covert recognition was also reflected in enhanced autonomic activity and the forced selection of faces based on emotional cues or a vague sense of familiarity. This suggests that neural structures involved in the processing of emotional or social cues mediate the covert recognition present in FE.

Manuscript received 26 July 2001
Revised manuscript received 23 April 2003
Revised manuscript accepted 29 May 2003

\section{REFERENCES}

Allison, T., Puce, A., Spencer, G., \& McCarthy, G. (1999). Electrophysiological studies of human face perception. I: Potentials generated in occipitotemporal cortex by face and non-face stimuli. Cerebral Cortex, 9, 415-430.

Baudena, P., Halgren, E., Heit, G., \& Clarke, J. M. (1995). Intracerebral potentials to rare tartget and distractor auditory and visual stimuli. III. Frontal cortex. Electroencephalography and Clinical Neurophysiology, 94, 251-264.

Bauer, R. M. (1984). Autonomic recognition of names and faces in prosopagnosia: A neuropsychological application of the guilty knowledge test. Neuropsychologia, 22, 457-469.

Barton, J. J., Cherkasova, M., \& O’Connor M. (2001). Covert recognition in acquired and developmental prosopagnosia. Neurology, 57, 1161-1168.

Bentin, S., Allison, T., Puce, A., Perez, A., \& McCarthy, G. (1996). Electrophysiological studies of face perception in humans. Journal of Cognitive Neuroscience, 8, 551-556.

Bentin, S., \& Deouell, L. Y. (2000). Structural encoding and identification in face processing: ERP evidence for separate mechanisms. Cognitive Neuropsychology, 17, 35-54.

Bentin, S., Deouell, L. Y., \& Soroker, N. (1999). Selective streaming of visual information in face 
recognition: Evidence from developmental prosopagnosia. Neuroreport, 10, 823-827.

Benton, A. L., \&Van Allen, M. W. (1968). Impairment in facial recognition in patients with cerebral disease. Cortex, 4, 344-358.

Bernat, E., Shevrin, H., \& Snodgrass, M. (2001). Subliminal visual oddball stimuli evoke a P300 component. Clinical Neurophysiology, 112, 159-171.

Blair, R., \& Karniski, W. (1993). An alternative method for significance testing of waveform difference potencial. Psychophysiology, 30, 518-524.

Bobes, M. A., Lopera, F., García, M., Díaz-Comas, L., Galán, L., \& Valdés-Sosa, M. (2003). Covert matching of unfamiliar faces in a case of prosopagnosia: An ERP study. Cortex, 39, 41-56.

Bobes, M. A., Valdés-Sosa, M., \& Olivares, E. (1994). An ERP study of expectancy violation in face perception. Brain and Cognition, 26, 1-22.

Bodamer, A. (1947). Die prosopagnosia. Archiv für Psychiatrie und Nervenkrankheiten, 179, 6-53.

Brazdil, M., Rektor, I., Daniel, P., Dufek, M., \& Jurak, P. (2001). Intracerebral event-related potentials to subthreshold target stimuli. Clinical Neurophysiology, 112, 650-661.

Brazdil, M., Rektor, I., Dufek, M., Daniel, P., Jurak, P., \& Kuba, R. (1999). The role of frontal and temporal lobes in visual discrimination task-depth ERP studies. Neurophysiology Clinic, 29, 339-350.

Breen, N., Caine, D., \& Coltheart, M. (2000) Models of face recognition and delusional misindentification: A critical review. Cognitive Neuropsychology, 17, 55-72.

Breen, N., \& Coltheart, M. (2001), A two way window on face recognition. Trends in Cognitive Sciences, 5, 234.

Brett, M., Leff, A. P., Rorden, C., \& Ashburner, J. (2001). Spatial normalization of brain images with focal lesions using cost function masking. Neuroimage, 14, 486-500.

Bruce, V., \& Young, A. W. (1986). Understanding face recogntion. British Journal of Psychology, 77, 305-327.

Bruyer, R. (1991). Covert face recognition in prosopagnosia: A review. Brain and Cognition, 15, 223-235.

Bruyer, R., Laterre, C., Seron, X., Feyereisen, P., Strypstein, E., Pierrard, E., \& Rectem, D. (1983). A case of prosopagnosia with some preserved covert remembrance of familiar faces. Brain and Cognition, 2, 257-284.

Bruyer, R., \& Schweich, M. (1991). A clinical test battery of face processing. International Journal of Neuroscience, 61, 19-30.
Burton, A. M., Young, A. W., Bruce, V., Johnston, R., \& Ellis, A. W. (1991).Understanding covert recognition. Cognition, 39, 126-166.

Comerchero, M. D., \& Polich, J. (1999). P3a and P3b from typical auditory and visual stimuli. Clinical Neurophysiology, 110, 24-30.

Courchesne, E., Hillyard, S. A., \& Galambos, R. (1975). Stimulus novelty, task relevance and the visual evoked potential in man. Electroencephalography and Clinical Neurophysiology, 39, 131-143.

Critchley, H. D., Elliot, R., Mathias, C. J., \& Dolan, R. J. (2000). Neural activity relating to generation and representation of galvanic skin conductance response: A functional magnetic resonance imaging study. Journal of Neuroscience, 20, 3033-3040.

De Haan, E. H. F., Bauer, R. M., \& Greve, K. W. (1992). Behavioural and psychophysiological evidence for covert face recognition in a prosopagnosic patient. Cortex, 28, 77-95.

De Haan, E. H. F., Young, A. W., \& Newcombe, F. (1987). Face recognition without awareness. Cognitive Neuropsychology, 4, 385-415.

Deouell, L., Hämäläinen, H., \& Bentin, S. (2000). Unilateral neglect after right-hemisphere damage: Contributions from event-related potentials. Audiology and Neuro-Otology, 5, 225-234.

DeRenzi, E., Faglioni, P., Grossi, D., \& Nichelli, P. (1991). Apperceptive and associative forms of prosopagnosia. Cortex, 27, 213-221.

Devrim, M., Demiralp, T., \& Kurt, A. (1997). The effects of subthreshold visual stimulation on P300 response. Neuroreport, 8, 3113-3117.

Diamond B. J., Valentine, T., Mayes, A. R., \& Sandel, M. E. (1994). Evidence of covert recognition in a prosopagnosic patient. Cortex, 30, 377-393.

Donchin, E., \& Coles, M. G. H. (1988). Is the P300 component a manifestation of context updating? The Behavioral and Brain Science, 11, 357-374.

Eimer, M. (2000a). Event related brain potentials distinguish processing stages involved in face perception and recognition. Clinical Neurophysiology, 111, 694-705.

Eimer, M. (2000b). Effects of face inversion on the structural encoding and recognition of faces: Evidence from event-related potentials. Cognitive Brain Research, 10, 145-158.

Eimer, M., \& McCarthy, R. (1999). Prosopagnosia and structural encoding of faces: Evidence from event related potentials. Neuroreport, 10, 255-259.

Ellis, H. D., \& Lewis, M. B. (2001), Capgrass delusion: A window on face recognition. Trends in Cognitive Sciences, 5, 149-156. 
Escera, C., Alho, K., Winkler, I., \& Näätänen, R. (1998). Neural mechanisms of involuntary attention to acoustic novelty and change. Journal of Cognitive Neuroscience, 10, 590-604.

Etcoff, N. L., Freeman, R., \& Cave, K. R. (1991). Can we loose memories for faces? Content specificity and awareness in a prosopagnosic. Journal of Cognitive Neuroscience, 3, 25-41.

Farah, M. J. (1990). Visual agnosia. Cambridge, MA: MIT Press.

Farah, M. J., O’Reilly, R. C., \& Vecera, S. P. (1993). Dissociated overt and covert recognition as an emergent property of a lesioned neural network. Psychological Review, 100, 571-588.

Greve, K. W., \& Bauer, R. M. (1990). Implicit learning of new faces in prosopagnosia: An application of the mere exposure paradigm. Neuropsychologia, 28, 1035-1041.

Hadjikhani, N., \& De Gelder, B. (2002). Neural basis of prosopagnosia: An fMRI study. Human Brian Mapping, 16, 176-182.

Halgren, E., Dale, A. M., Sereno, M. I., Tootell, R. B., Marinkovic, K., \& Rosen, B. R. (1999). Location of human face-selective cortex with respect to retinotopic areas. Human Brain Mapping, 7, 29-37.

Haxby, J., Hoffman, E., \& Gobbini, I. (2000). The distributed human neural system for face perception. Trends in Cognitive Science, 4, 223-233

Haxby, J., Horwitz, B., Ungerleider, L. G., Maisog, J. M., Pietrini, P., \& Grady, C. L. (1994). The functional organization of human extrastriate cortex: A PET-rCBF study of selective attention to face and locations. Journal of Neuroscience, 14, 6336-6353.

Haxby, J., Ungerleider, L. G., Clark, V. P., Schouten, J. L., Hoffman, E. A., \& Martin, A. (1999). The effect of face inversion on activity in human neural systems for face and object perception. Neuron, 22, 189-199.

Hillyard, S. A., \& Picton, T. W. (1987). Electrophysiology of cognition. In F. Plum (Ed.), Handbook of physiology. Section 1: The nervous system. Volume $V$. Higher functions of the nervous system (pp. 519-584). Bethesda, MD: American Physiological Society.

Hoffman, E., \& Haxby, J. (2000). Distinct representations of eye gaze and identity in the distributed human neural system for face perception. Nature Neuroscience, 3, 80-84.

Huang, J. C., Nicholson, C., \& Okada, Y. C. (1990). Distortion of magnetic evoked fields and surface potentials by conductivity differences at boundaries in brain tissue. Biophysical Journal, 57, 1155-1166.
Ito, H., Sugiyama, Y., Mano, T., Okada, H., Matsukawa, T., \& Iwase, S. (1996). Skin sympathetic nerve activity and event related potentials during auditory oddball paradigm. Journal of Autonomous Nervous System, 60, 129-135.

Kanwisher, N., McDermott, J., \& Chun, M.M. (1997). The fusiform face area: A module in human extrastriate cortex specialized for face perception. Journal of Neuroscience, 17, 4302-4311.

Knight, R., \& Grabowecky, M. (1995). Escape from linear time: Prefrontal cortex and conscious experience. In M. Gazzaniga (Ed.), Cognitive neuroscience (pp. 1357-1371). Cambridge, MA: MIT Press.

Köhler, S., \& Moscovitch, M. (1997). Unconscious visual processing in neuro-psychological syndromes: A survey of the literature and evaluation of models of consciousness. In M. Rugg (Ed.), Cognitive neuroscience (pp. 305-373). Cambridge, MA: MIT Press.

Kutas, M., McCarthy, G., \& Donchin, E. (1977). Augmenting mental chronometry: The P300 as a measure of stimulus evaluation time. Science, 197, 792-795.

Ledoux, J. E. (1995). In search of an emotional system in the brain: Leaping from fear to emotion and consciousness. In M. Gazzaniga (Ed.), Cognitive neuroscience (pp. 1049-1062). Cambridge, MA: MIT Press.

Lewis, M. B., \& Ellis, H. D. (2001). A two-way window on face recognition. Reply to Breen et al. Trends in Cognitive Sciences, 5, 235.

Lopera, F., \& Ardila, A. (1992). Prosopamnesia and visuolimbic disconnection syndrome: A case study. Neuropsychology, 6, 3-12.

Marotta, J. J., Genovese, C. R., \& Behrmann, M. (2001). A functional MRI study of face recognition in patients with prosopagnosia. Neuroreport, 12, 1581-1587.

McCarthy, G., Puce, A., Belger, A., \& Allison, T. (1999). Electrophysiological studies of human face perception. II: Response properties of face-specific potentials generating in occipitotemporal cortex. Cerebral Cortex, 9, 431-444.

McCarthy, G., \& Wood, C. C. (1985). Scalp distributions of event related potentials: An ambiguity associated with analysis of variance models. Electroencephalography and Clinical Neurophysiology, 62, 203208.

McNeil, J. E., \& Warrington, E. K. (1991). Prosopagnosia: A reclassification. Quarterly Journal of Experimental Psychology, 43A, 267-287.

Mycroft, R. H., Mitchell, D. C., \& Kay, J. (2002). An evaluation of statistical procedures for comparing an 
individual's performance with that of a group of controls. Cognitive Neuropsychology, 19, 291-299.

Näätänen, R. (1992). Attention and brain function. Hillsdale, NJ: Lawrence Erlbaum Associates Inc.

Newcombe, F. A., Young, A. W., \& De Haan, E. H. F. (1989). Prosopagnosia and object agnosia without covert recognition in a prosopagnosic patient. Neuropsychologia, 27, 179-191.

O'Reilly, R. C., \& Farah, M. (1999). Simulation and explanation in neuropsychology and beyond. Neuropsychology, 16, 49-72.

Perez-Abalo, M. C., Rodríguez, R., Bobes, M. A., Gutierrez, J., \&Valdés-Sosa, M. (1994). Brain potentials and availability of semantic and phonological codes over time. Neuroreport, 5, 2173-2177.

Picton, T. W. (1992). The P300 wave of the human event-related potentials. Journal of Clinical Neurophysiology, 9, 456-479.

Puce, A., Allison, T., Bentin, S., Gore, J. C., \& McCarthy, G. (1998). Temporal cortex activation of humans viewing eye and mouth movements. Journal of Neuroscience, 18, 2188-2199.

Puce, A., Allison, T., \& McCarthy, G. (1999). Electrophysiological studies of human face perception. III: Effects of top-down processing of facespecific potentials. Cerebral Cortex, 9, 445-458.

Renault, B., Signoret, J., Debruille, B., Breton, F., \& Bolgert, F. (1989). Brain potentials reveal covert facial recognition in prosopagnosia. Neuropsychologia, 27, 905-912.

Rizzo, M., Hurtig, R., \& Damasio, A. R. (1987). The role of scanpath in facial recognition and learning. Annals of Neurology, 22, 41-45.

Rorden, C., \& Brett, M. (2000). Stereotaxic display of brain lesions. Behavioral Neurology, 12, 191-200.

Rossion, R. B., Campanella, S., Gomez, C. M., Delinte, A., Debatise, D., Liard, L., Dubois, S., Bruyer, R., Crommelineck, M., \& Guerit, J. M. (1999). Task modulation of brain activity related to familiar and unfamiliar face processing: An ERP study. Clinical Neurophysiology, 110, 449-462.

Ruchkin, D. S., Johnson, R., Canoune, H. L., Ritter, W., \& Hammer, M. (1990). Multiple source of P3b associated with different types of information. Psychophysiology, 27, 157-176.

Rugg, M., \& Coles, M. G. H. (1995). The ERP and cognitive psychology: Conceptual issues. In M. D. Rugg \&M. D. Coles (Eds.), Electrophysiology of mind. New York: Oxford University Press.

Schroger, E., Giard, M. H., \& Wolff, C. (2000). Auditory distraction: Event-related potential and behavioral indices. Clinical Neurophysiology, 111, 1450-1460.

Schweinberger, S. R., \& Burton, M. (2003) Covert recognition and the neural system for face processing Cortex, 39, 9-30

Schweinberger, S. R., Pickering, E. C., Jentzsch, I., Burton, M., \& Kaufmann, J. M. (2002). Eventrelated brian potential evidence for a response of inferior temporal cortex of familiar face repetitions. Cognitive Brain Research, 14, 398-409.

Sergent, J., Ohta, S., \& MacDonald, B. (1992). Functional neuroanatomy of face and object processing. Brain, 115, 15-36

Spencer, K. M., Dien, J., \& Donchin, E. (1999). A componential analysis of the ERP elicited by novel events using a dense electrode array. Psychophysiology, 36, 409-414.

Squires, K. C., Hillyard, S. A., \& Lindsay, P. L. (1973). Vertex potentials evoked during auditory signal detection: Relation to decision criteria. Perception and Psychophysics, 14, 265-272.

Squires, N., Squires, K., \& Hillyard, S.A. (1975). Two varieties of long-latency positive waves evoked by unpredictable auditory stimuli in man. Electroencphalography and Clinical Neurophysiology, 38, 387-401.

Stone, A., \& Valentine, T. (2003). Perspectives on prosopagnosia and models of face recognition. Cortex, 39, 31-40

Stone, A., Valentine, T., \& Davis, R. (2001). Face recognition and emotional valence: Processing without awareness by neurological intact participants does not simulate covert recognition in prosopagnosia. Cognitive, Affective and Behavioral Neuroscience, 1, 183-191.

Tranel, D., Bechara, A., \& Damasio, A. (2000). Decision making and the somatic marker hypothesis. In M. Gazzaniga (Ed.), The new cognitive neuroscience (pp. 1047-1061). Cambridge, MA: MIT Press

Tranel, D., \& Damasio, A. R. (1985). Knowledge without awareness: An autonomic index of facial recognition by prosopagnosics. Science, 228, 1453-1454.

Tranel, D., \& Damasio, A. R. (1988). Non-conscious face recognition in patients with face agnosia. Behavioral Brain Research, 30, 235-249.

Tranel, D., Damasio, H., \& Damasio, A. R. (1995). Double dissociation between overt and covert face recognition. Journal of Cognitive Neuroscience, 7, 425-432.

Verleger, R. (1988). A critique of the context updating hypothesis and an alternative interpretation of P3. The Behavioral and Brain Science, 11, 343-427. 
BOBES ET AL.

Young, A. W. (1992). Face recognition impairments. Philosophical Transactions of the Royal Society, London, B335, 47-54.

Young, A. W., \& Burton, A. M. (1999). Simulating face recogntion: Implication for modelling cognition. Cognitive Neuropsychology, 16, 1-48.

Young, A. W., Hellawell, D., \& De Haan, E. H. F. (1988). Cross-domain semantic priming in normal subjects and a prosopagnosic patient. Quarterly Journal of Experimental Psychology, 40A, 561-580.

Zhan, T. P., Grafman, J., \& Tranel, D. (1999). Frontal lobe lesions and electrodermal activity: Effects of significance. Neuropsychologia, 37, 1227-1241. 